\title{
The effectiveness of FRP strips in repairing moderately and severely damaged RC beam- column connections
}

\section{Rijun Shrestha}

Research Associate, School of Civil and Environmental Engineering, Faculty of Engineering and Information Technology, University of Technology Sydney, Australia

Scott T. Smith

Associate Professor, Department of Civil Engineering, Faculty of Engineering, The University of Hong Kong, China

\section{Bijan Samali}

Professor, School of Civil and Environmental Engineering, Faculty of Engineering and Information Technology, University of Technology Sydney, Australia

An effective means to increase the shear resistance of shear deficient reinforced-concrete (RC) beam-column connections is by bonding fibre-reinforced polymer (FRP) composites. The majority of research to date has focused on the strengthening of two-dimensional reinforced-concrete connections with fibre-reinforced polymer; that is, the strengthening of virgin (undamaged) connections. This paper reports the results of tests on the effectiveness of fibre-reinforced polymer strips in repairing two-dimensional connections with different degrees of damage. The results of tests assessing the effectiveness of fibre-reinforced polymer strips in strengthening virgin connections are also reported. All test specimens are extensively instrumented and their behaviour and failure comprehensively documented. In the case of the repaired specimens, instrumentation is concentrated on the fibre-reinforced polymer around the damage region, thus enabling the strength contribution and behaviour of the fibre-reinforced polymer repair to be closely monitored. The results of this experimental programme enable a better understanding of the strengthening and repair effect of fibre-reinforced polymer strips in reinforced-concrete beam-column connections, and the results will also facilitate the future development and calibration of analytical and numerical models.

\section{Introduction}

Reinforced concrete (RC) structures, designed prior to the implementation of earthquake design standards, were generally designed to resist gravity loads only. The beam-column connections in these gravity-load-designed structures may be susceptible to failure during a seismic attack as they may not possess sufficient shear strength in the joint region where the beam(s) frames into the column owing to a lack of internal steel reinforcement. A need has therefore arisen not only to strengthen existing connections but also to look into options for repair and rehabilitation of existing but damaged connections.

The use of externally bonded fibre-reinforced polymer (FRP) composites to strengthen shear deficient connections has been proven to be effective from past studies; however, the majority of such studies has concentrated on the strengthening of undamaged (virgin) two-dimensional connections. External (i.e. one beam framing into a column) and internal (i.e. two beams framing into a column) connections, with insufficient shear strength (e.g. A1Salloum and Almusallam, 2007; Antonopoulos and Triantafillou, 2003; Shrestha et al., 2009) or longitudinal beam reinforcement anchorage capacity (e.g. Ghobarah and El-Amoury, 2005; Grana- ta and Parvin, 2001), have been strengthened with various arrangements of externally bonded FRP and tested to date. A comprehensive review of existing experimental research on strengthening RC beam-column connections with FRP, in addition to an evaluation of the effectiveness of the strengthening schemes, is given in Smith and Shrestha (2006). A comprehensive review of non-FRP-strengthening technologies, as well as some FRP ones, is given in Engindeniz et al. (2005). In addition, twodimensional connections have been predominantly tested to date because

(a) three-dimensional connections are difficult to construct and test and the loading sequence is especially complicated, and

(b) two-dimensional connections do not possess the positive confinement effect that transverse beams in three-dimensional connections provide to the joint region.

For convenience, the majority of tests on FRP-strengthened connections and indeed the majority of work on plain RC connections (Paulay and Priestley, 1992) to date have, therefore, been conducted on two-dimensional connections. 
Surprisingly, little research appears to exist in the open literature on the repair of damaged RC beam-column connections with FRP composites. Of the limited work, control (unstrengthened) connections have been loaded to certain levels in order to inflict different degrees of damage ranging from moderate damage to severe damage (Tsonos and Styliandis, 2002). The repair techniques have in turn been dependent on the level of damage, namely (a) cosmetic repair using non-shrink mortar for moderately damaged connections (Tsonos and Styliandis, 2002), to (b) more structural repair using crack injection for more severely damaged connections (Al-Salloum and Almusallam, 2007; Tsonos and Styliandis, 2002). It has been demonstrated that the repair techniques using FRP are effective in restoring the strength of the connections, while increased energy dissipation capacity and change in failure mode (e.g. from joint shear failure in control connection to beam hinging in repaired connection (Al-Salloum and Almusallam, 2007; Tsonos and Styliandis, 2002)) has also been achieved. However, limited information on the severity of the damage prior to the repair and also the actual repair technique has been reported in all studies, and thus a real need exists to report more rigorously on the damage process and subsequent behaviour of the FRP repair. Of particular note with respect to the FRP repair, studies to date have reported the repaired connection to fail away from the FRP repair region. As a result, the true effect of the FRP has not been able to be completely quantified.

This paper reports the results of tests on two-dimensional external $\mathrm{RC}$ connections weak in shear, which are moderately or severely damaged and then repaired with externally bonded FRP strips. These tests are part of a larger set of tests which focus not only on the repair but also on the strengthening of shear deficient connections. A much more comprehensive account of the entire testing regime is provided in Shrestha (2009). The repair and strengthening schemes reported in this paper were chosen specifically upon consideration of the ease and viability in practical application to two-dimensional connections. FRP strips were chosen over sheets as the strips make it easier to observe the progression of cracking in the joint region in addition to detecting the occurrence of FRP debonding. In addition, strips have the potential for wider application to three-dimensional connections and are hence deemed a promising solution. In the three-dimensional case, slots will need to be drilled into the beams transverse to the joint for insertion of the strips; however, such research is outside the scope of this study. All test specimens in this study were extensively instrumented with electric resistance strain gauges and linear variable displacement transducers (LVDTs). Also, they were subjected to monotonic loading in order to make the assessment of the FRP contributions more easily observed and understood, as traditionally applied cyclic (push-pull) loading make cracking in the concrete as well as the behaviour of the FRP more difficult to monitor. The tests on repaired connections are then compared with tests on strengthened (virgin) connections, which are virtually identical in geometry and material properties, thus enabling the effectiveness of the FRP repair to be accurately evaluated. It is important to note here that the repair undertaken in this study is largely cosmetic. The repair fills in larger cracks and also replaces lost concrete cover. The repair, however, does not attempt significantly to restore the structural integrity of the original $\mathrm{RC}$ connection, unlike the technique of crack injection, for example (Al-Salloum and Almusallam, 2007; French et al., 1990). The cosmetic repair is intended to provide a suitable working surface for the FRP strips to be applied. The tests will, therefore, largely enable the contribution of the FRP alone to be accurately quantified. The wealth of experimental data and physical observation reported in this paper will aid future researchers in the development of analytical and numerical models describing the behaviour of FRP-repaired and FRP-strengthened RC connections.

\section{Experimental details}

\section{General details of test specimens}

Three connections which have been subjected to different strengthening/repair histories are reported in this paper and summarised in Table 1. All connections possessed identical geometric and internal steel reinforcement details, as shown in Figure 1, and had no shear reinforcement in the joint region. All test connections were designed to ensure a hierarchy of strength which dictated shear failure in the joint region (with and without FRP) followed by beam flexural failure then column flexural failure. Of course, in reality, hinging in the beam (in accordance with the principal of 'weak-beam strong-column' behaviour) is the preferred failure mode. Two of the connections were ulti-

\begin{tabular}{llll} 
Specimen & $\begin{array}{l}\text { Specimen condition prior } \\
\text { to FRP application }\end{array}$ & FRP scheme & Connection history \\
\hline UM1 & Control & - & \\
SM1 & Virgin & Column strips & - \\
SM2 & Virgin & Beam strips & - \\
RM1 & Moderately damaged & Column strips & Repaired UM1 \\
RM2 & Severely damaged & Beam strips & Repaired SM2
\end{tabular}

Table 1. Test specimens 


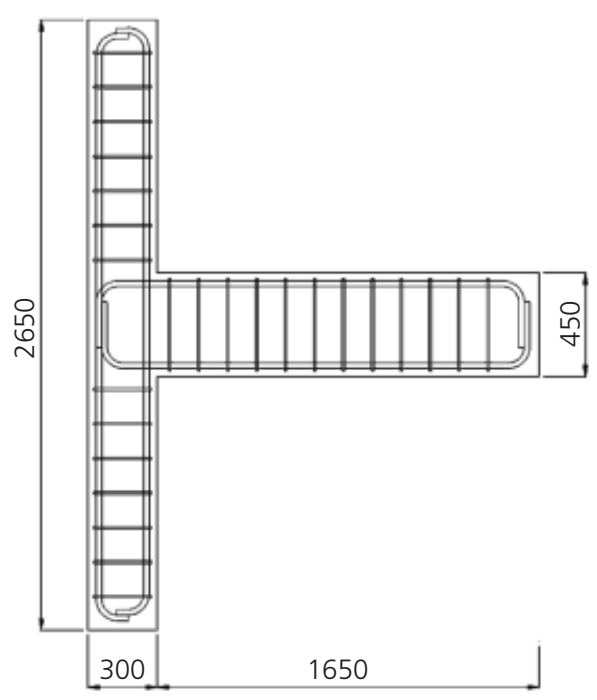

(a)
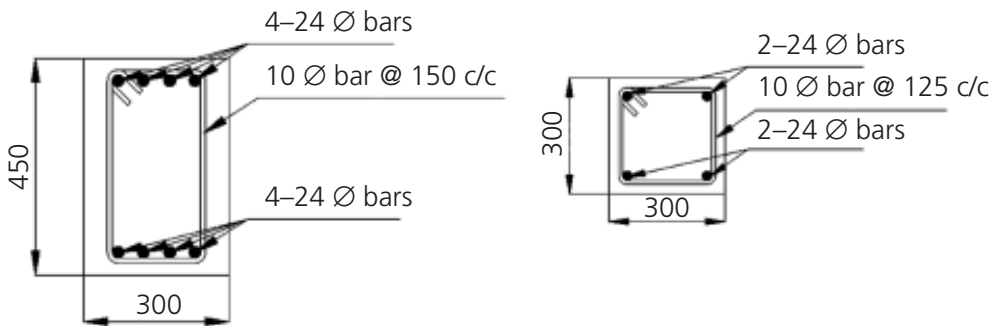

(b)

(c)

Figure 1. Connection geometry and reinforcement details:

(a) geometry; (b) beam section; (c) column section

mately repaired with either column (Figure 2(a): herein referred to as the 'column strip scheme') or beam oriented (Figure 2(b): herein referred to as the 'beam strip scheme') FRP strips. Strips were selected, as opposed to continuous sheets, in order for the strips and the surrounding joint concrete to be accurately monitored. Complete details of the test specimens are provided in

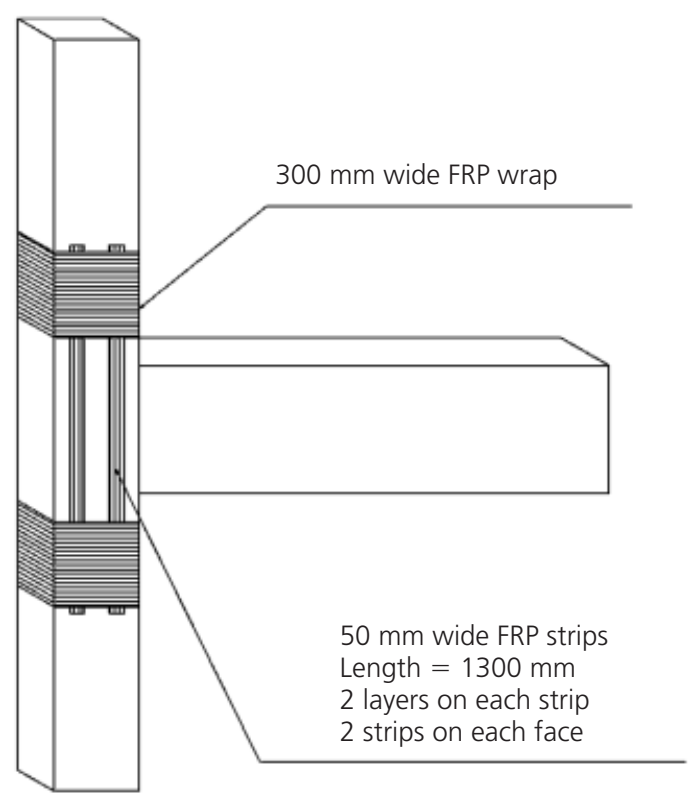

(a)

Figure 2. FRP strengthening schemes: (a) column strips scheme (SM1, RM1); (b) beam strips scheme (SM2, RM2)
Shrestha (2009) with the most relevant results and observations reported in this paper.

\section{Test set-up and loading}

All connections were tested with the column component orientated parallel to the ground while the load was applied to the free

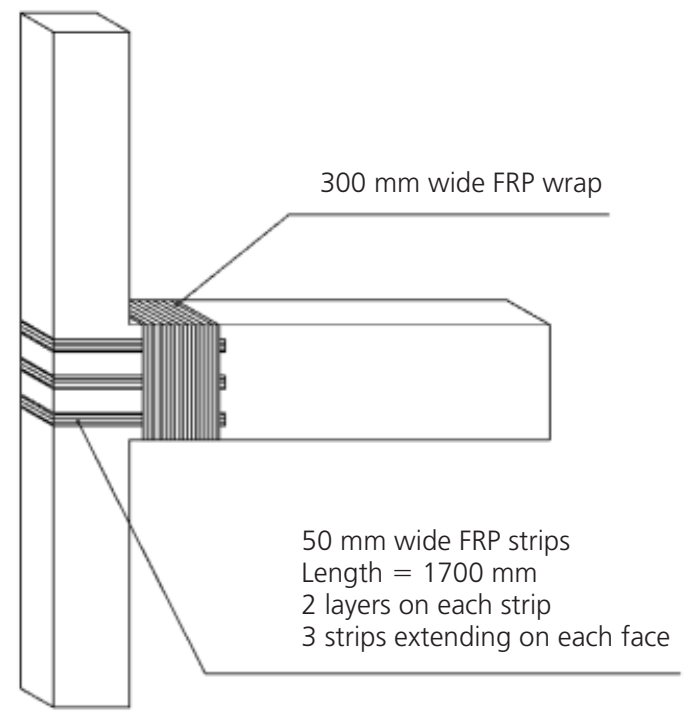

(b) 
end of the vertically orientated beam. The connection was mounted on a stiff test frame with hinge supports at both ends of the column as shown in Figure 3. An axial load of $180 \mathrm{kN}$ (equal to $8 \%$ of the gross axial load capacity of the column and representative of a typical floor load) was applied to the column using a hydraulic jack embedded in a self-reacting frame of high strength Macalloy bars anchored to both ends of the column.

A monotonically increasing load was applied to the beam tip at a rate of $0.2 \mathrm{~mm}$ per second, in ram displacement control, through an actuator mounted on a stiff reaction frame. The ram was displaced until the beam-tip load (herein referred to as 'load') reached increments of $10 \mathrm{kN}$. At each load increment the load was paused and cracks were marked on the test specimens. The load was applied continuously until failure when no new significant cracks were observed to form and at approximately $50 \%$ of the theoretical peak load carrying capacity of the connection.

\section{Specimens UM1 and RM1}

The first repaired connection, RM1, was a repair of the unstrengthened control connection UM1 in which the control specimen experienced shear failure in the joint region after being subjected to monotonic loading. In the early stage of the control test (UM1), minor flexural cracks were observed in the tension face of the beam followed by cracks at the adjacent beamcolumn corner. With further increase in the load, a major diagonal shear crack was observed in the joint region at a load of $70 \mathrm{kN}$ (beam-tip displacement, herein 'displacement', of $13.2 \mathrm{~mm}$ ). The peak load carrying capacity of $96.4 \mathrm{kN}$ (displacement of $27.7 \mathrm{~mm}$ ) was reached and no further increase in load was observed with increased displacement. The control specimen was then immediately unloaded and removed from the test frame in order to apply the FRP repair. The connection experienced considerable shear cracking in the joint region, although, the damage was not excessive, as shown in Figure 4(a) (see diagonal cracks in the boxed area) and Figure 5. This connection is herein referred to as 'moderately damaged' and distinction is made in Figure 5 between major cracks (cracks of large width) and minor cracks (cracks of small width). Prior to application of the FRP, the loose concrete in the cracked joint region was removed and the surfaces cleaned by spraying with compressed air; however, it should be noted from Figure 4(a) that little or no concrete cover in the joint region had fallen off, thus indicating the less severe nature of the damage. Voids left after removal of damaged concrete were filled with an epoxy adhesive, known as Megapoxy $\mathrm{PF}$, prior to application of the FRP repair. According to the manufacturer's specification, the epoxy adhesive had a setting time of seven minutes and attained more than half of its ultimate strength within $15 \mathrm{~min}$ of mixing. As the extent of damage and the size of the major cracks were not excessive, repair adhesive, as opposed to repair mortar, was deemed suitable to patch up the damaged region sufficiently for the FRP repair to be adequately applied.

Figures 4(b) and 4(c) show connection RM1 which has been repaired with two two-layered column strips applied to both sides of the joint face, although no significant repair work is evident from these photographs. The ends of the column strips have been anchored by wrapping two layers of FRP around the perimeter of the column.

\section{Specimens SM2 and RM2}

The second repaired connection, RM2, was a repair of connection SM2. The virgin joint region of connection SM2 was originally strengthened with beam oriented strips and subjected to monotonic loading until failure. For SM2 the FRP strengthening

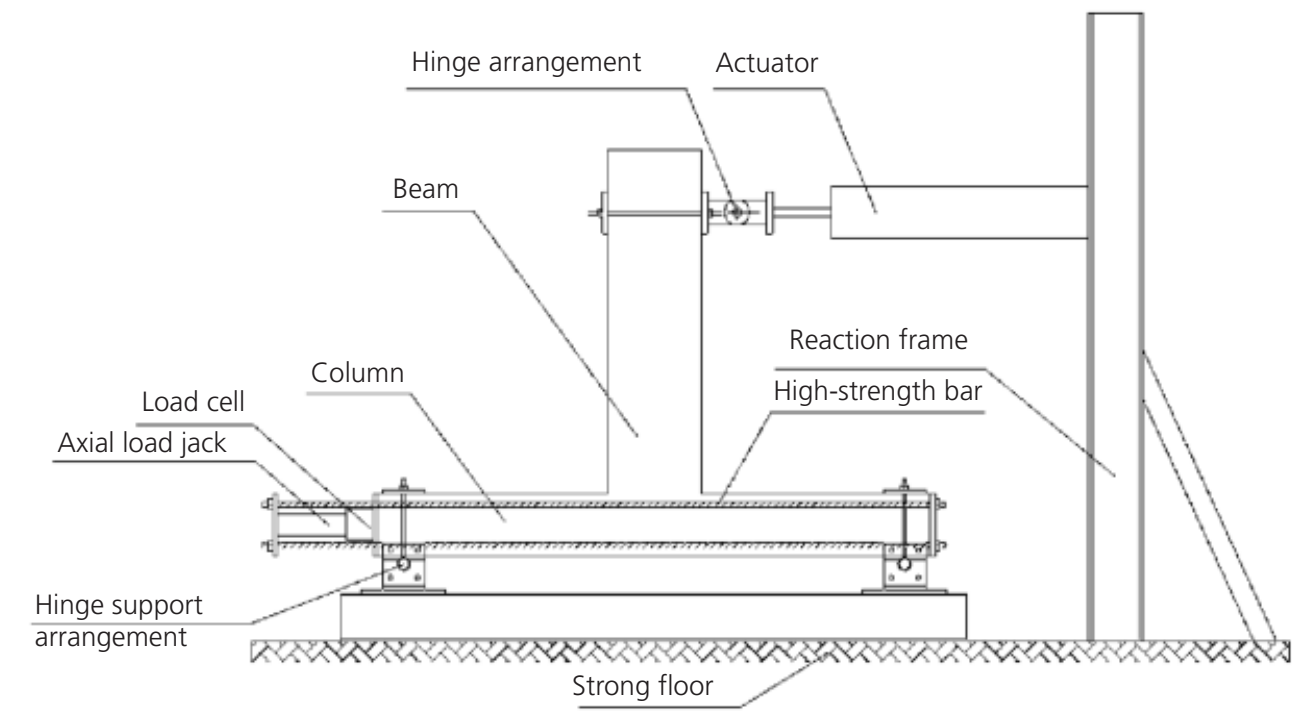

Figure 3. Test set-up 
The effectiveness of FRP strips in repairing moderately and severely damaged RC beam-column connections Shrestha, Smith and Samali

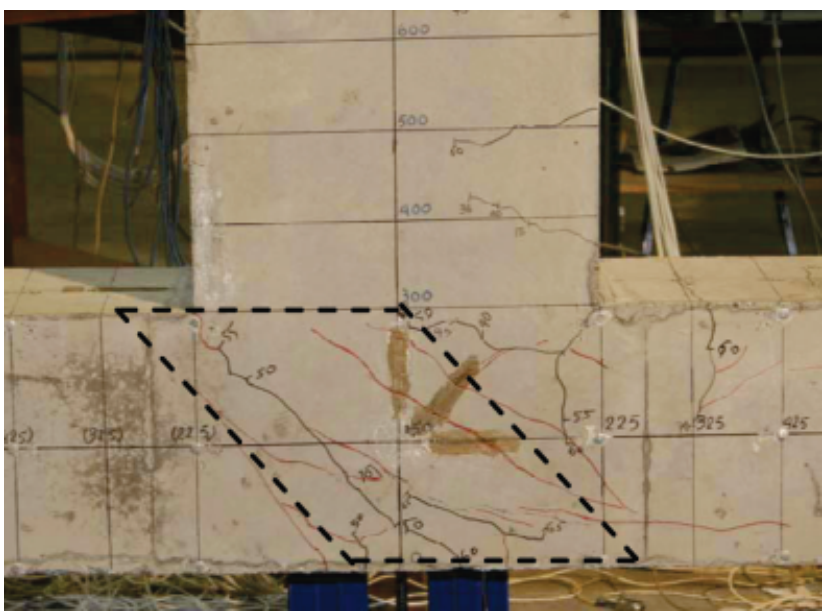

(a)

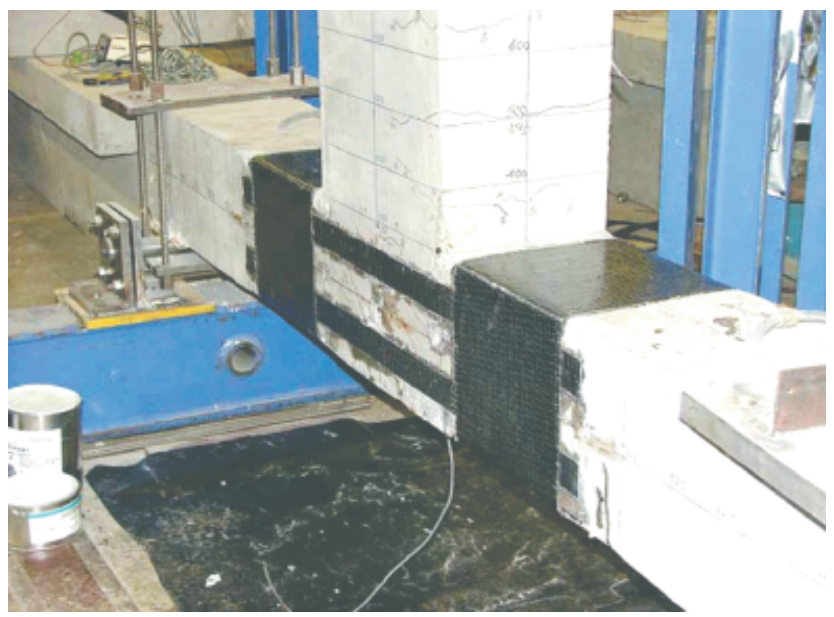

(b)

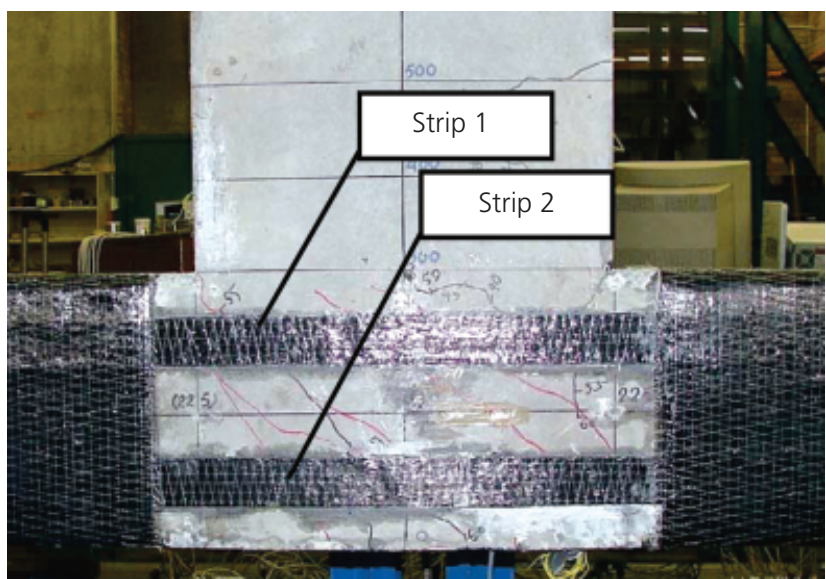

(c)

Figure 4. Column strip repair: moderately damaged connection: (a) pre-repair (UM1); (b) post-application of FRP repair (RM1); (c) close-up view of RM1 after repair consisted of three two-layered FRP strips oriented parallel to the beam and applied to both faces of the joint region. The FRP strips were continuous across the width of both joint faces and over the back face of the column, and anchored at both sides of the beam by wrapping, as shown in Figure 2(b). Connection SM2 reached a peak load of $122 \mathrm{kN}$ at $39 \cdot 1 \mathrm{~mm}$ displacement, and was then loaded until the load-carrying capacity had decreased to $40 \%$ of the peak load (i.e. load $=52 \mathrm{kN}$ and deflection $=92 \mathrm{~mm}$ ). Such considerable deformation produced quite extensive damage to the joint region and the immediate vicinity of the adjoining column and beams (herein 'severe damage'). At the peak load level of SM2, all three FRP strips had debonded, and when a deflection of $92 \mathrm{~mm}$ was reached all three strips had ruptured, generally in the bend portion around the joint edge.

To repair connection SM2 before being tested as connection RM2, all the loose and broken concrete was removed after the connection was unloaded and removed from the test frame. Owing to the severe level of damage, large voids remaining after removal of the damaged concrete were filled with repair mortar. Figure 6(a) shows the connection prior to the application of the repair mortar (heavily damaged areas circled with concrete cover removed), while Figure 7 is a detailed schematic of the cracking, damage and extent of repair mortar. After application of the mortar (Figure 6(b)), the connection was then repaired with FRP strips which were again oriented parallel to the beam (Figure $6(\mathrm{c}))$.

The repair mortar was selected based on the following characteristics

(a) good bond with the concrete and steel

(b) modulus of elasticity comparable to concrete (i.e. $30 \mathrm{GPa}$ )

(c) shrinkage compensation and significant early strength gain ( 1 day strength $=30 \mathrm{MPa})$

(d) ease of application of the mortar (capability of vertical or overhead application)

(e) ability to replace large quantities of lost concrete cover and core concrete (unlike the epoxy adhesive used for repairing specimen RM1).

The product MBrace EmacoS88C was selected; however, any like product could also be used.

\section{Specimen SM1}

Connection SM1 was strengthened with two FRP strips oriented parallel to the column on either face of the joint with anchorage provided by column FRP wraps. The primary mode of failure for connection SM1 was partial to complete debonding of the FRP strips, which was followed by joint shear failure (no strip rupture observed). A peak load of $103 \mathrm{kN}$ was reached at a deflection of $32 \mathrm{~mm}$, after which the load-carrying capacity of the connection was lost. This strengthened connection has been included in this study for comparison with the repaired connection RM1. 


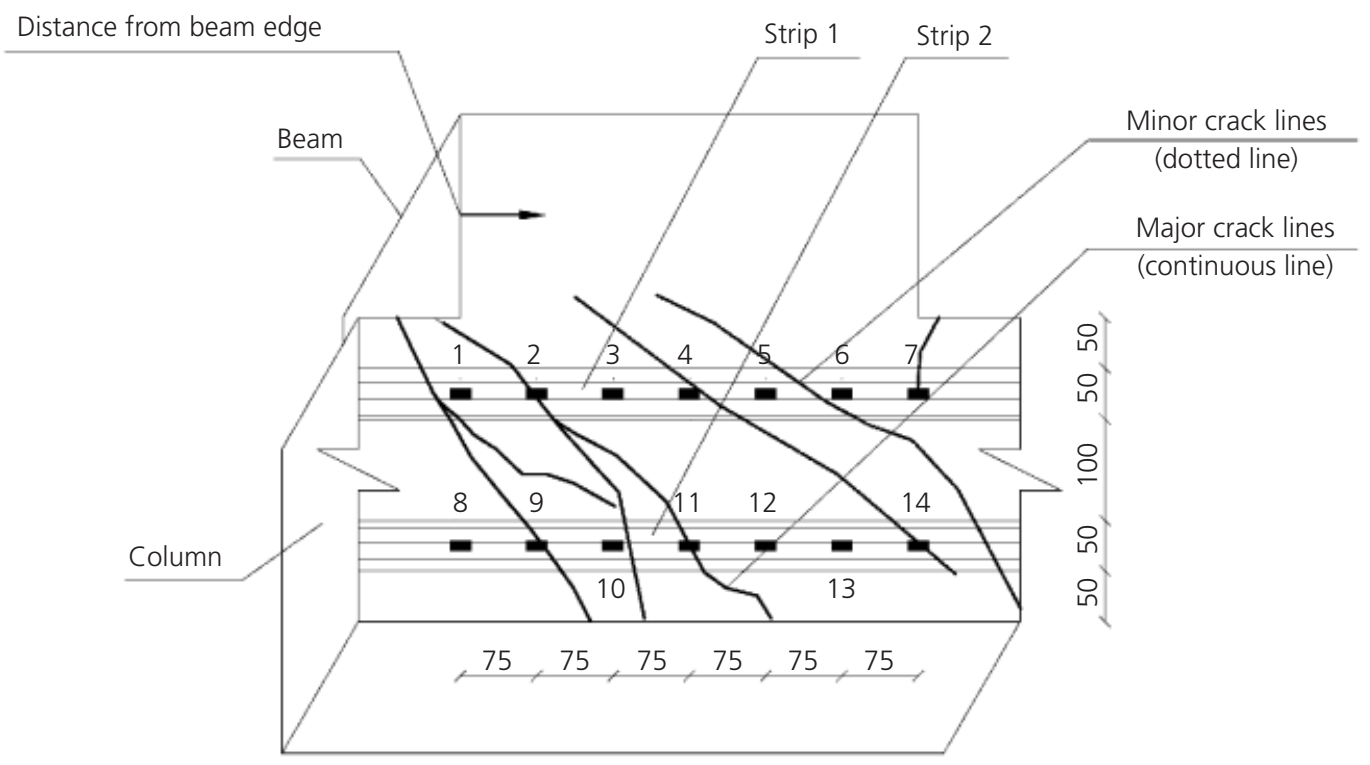

Figure 5. Column strip repair: extent of damage (and repair) and strain gauge layout of RM1 and SM1

\section{Instrumentation}

Three LVDTs were used to measure deflection along the length of the beam, while another nine LVDTs were used to monitor possible movement at key locations such as the supports and other critical regions of the test rig.

Strain gauges of $5 \mathrm{~mm}$ gauge length were adhered to the FRP in identical positions for the strengthened and corresponding repaired specimens, with centre-to-centre distances relative to the beam or column edges shown in Figure 5 (specimens SM1 and RM1), Figures 7(a) (specimen SM2) and Figure 7(b) (specimen RM2). For connection RM2, three gauges were slightly repositioned from their original SM2 position to coincide with the intersection of the FRP passing over existing cracks. The repositioned gauges are indicated with an 'A' in Figure 7(b) (i.e. gauges $5 \mathrm{~A}, 10 \mathrm{~A}$ and $13 \mathrm{~A}$ ) and one additional gauge was added to RM2 (i.e. gauge 16 in Figure 7(b)). Strain gauges of $50 \mathrm{~mm}$ gauge length were adhered to the concrete surface (not shown) and strain gauges of $5 \mathrm{~mm}$ gauge length were adhered to the internal steel reinforcing bars (not shown). The details of these non-FRP strain gauges are provided in Shrestha (2009).

\section{Material properties}

The material properties of the concrete for each of the three connections were determined in accordance with Australian Standard AS 1012. The results (averaged from three test specimens) for UM1, SM1, SM2 being: concrete cylinder compressive strength = $25 \cdot 4,25 \cdot 6,25 \cdot 6 \mathrm{MPa}$, elastic modulus $=24 \cdot 18,24 \cdot 08,24 \cdot 24 \mathrm{GPa}$, splitting strength $=2.82,2.51,2.67 \mathrm{MPa}$ and modulus of rupture $=4 \cdot 38,5 \cdot 31,4.54 \mathrm{MPa}$, respectively. As the concrete was mature at the time of testing specimens RM1 and RM2, further material testing was not undertaken. The manufacturer's specified properties of the repair mortar used to repair specimen RM2 were compressive strength $(1$ day $)=30 \mathrm{MPa}(30$ days $=70 \mathrm{MPa})$ and modulus of elasticity $=30 \mathrm{GPa}$, while the compressive strength of the epoxy adhesive used to repair specimen RM1 was $65 \mathrm{MPa}$.

The yield strengths of the longitudinal and transverse reinforcement (based on three test samples in accordance with ASTM ES042004 (ASTM, 2004)) were $532 \mathrm{MPa}$ and $332 \mathrm{MPa}$, respectively, while the tensile strength, elastic modulus and rupture strain of the carbon FRP strengthening and repair strips were $3120 \mathrm{MPa}$, $243 \mathrm{GPa}$ and $1 \cdot 1 \%$, respectively (based on five tensile tests on twolayered $15 \mathrm{~mm}$ wide coupons with carbon fibre sheets of $0 \cdot 117 \mathrm{~mm}$ nominal thickness per sheet, in accordance with ASTM 3039/D3039M 2000 (ASTM, 2000)).

\section{Experimental results}

Selected experimental results for repaired specimens RM1 and RM2 are reported in this section, as well as strengthened specimens SM1 and SM2. A more detailed account is given in Shrestha (2009).

\section{Behaviour and failure modes}

\section{Repaired connection RM1}

Existing cracks started to open up at the beam-column corner as the load was increased to $20 \mathrm{kN}$ in the second load increment. No new cracks were observed when the load reached $40 \mathrm{kN}$ and hence loading was continued with no further crack marking until failure. Localised debonding in FRP strip 1 was observed at loads of 87,95 and $100 \mathrm{kN}$ adjacent to the crack openings (strain gauge results will confirm localised debonding in fact occurred at a 
The effectiveness of FRP strips in repairing moderately and severely damaged RC beam-column connections Shrestha, Smith and Samali

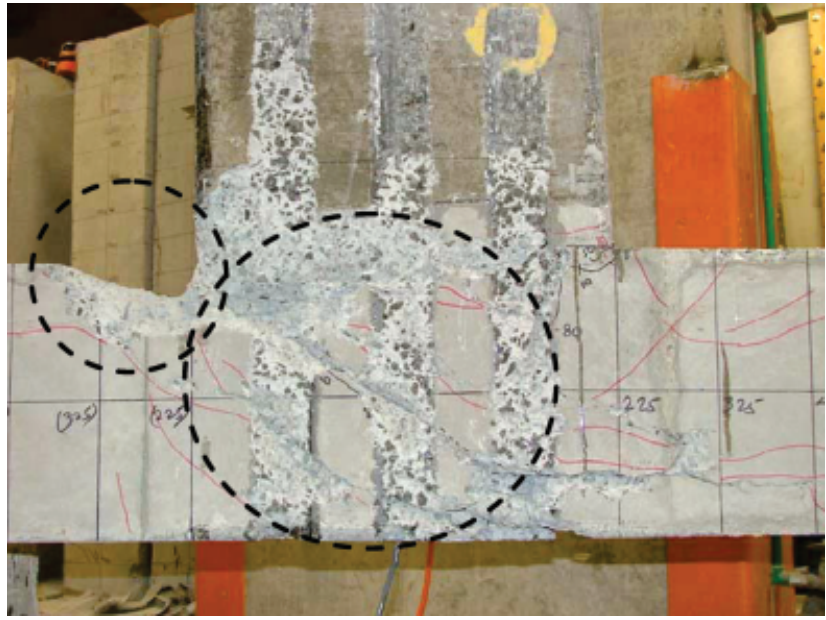

(a)

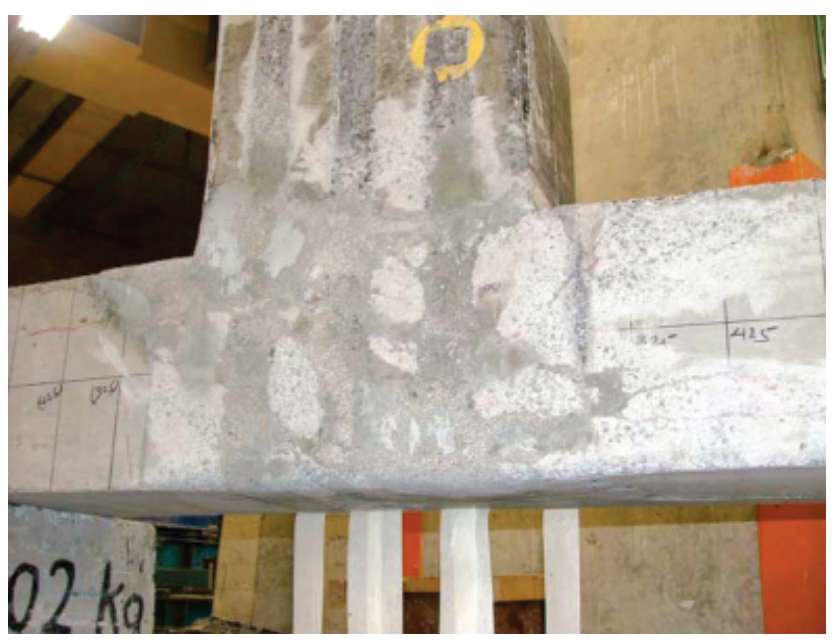

(b)

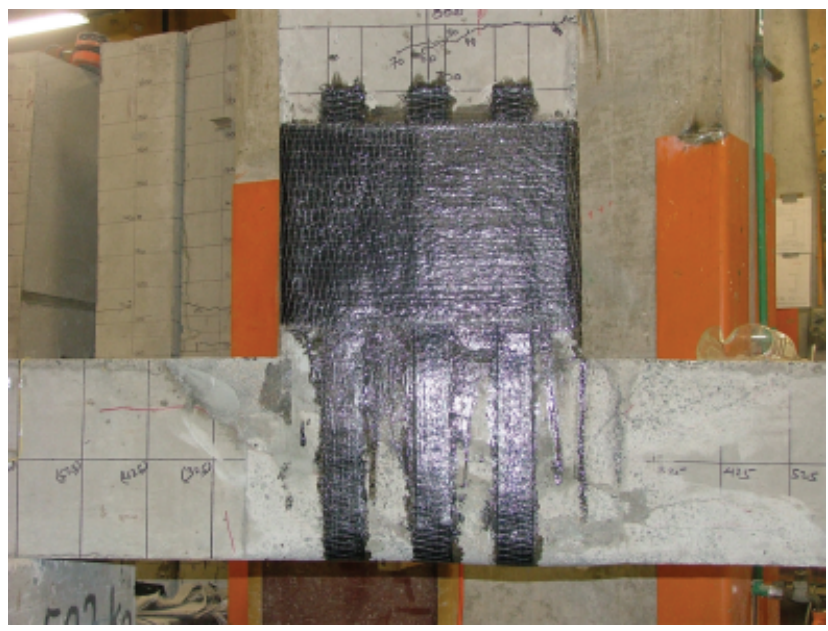

(c)

Figure 6. Beam strip repair: severely damaged connection:

(a) pre-repair (SM2 after removal of beam strips);

(b) post-application of repair mortar; (c) post-application of FRP repair (RM2) much lower load). A peak load of $106 \cdot 6 \mathrm{kN}$ was achieved at a displacement of $29.3 \mathrm{~mm}$ when complete debonding of FRP strip 1 on both faces of the connection between the end wraps occurred simultaneously, followed by the joint diagonal cracks opening widely, with spalling of the concrete at the column face adjacent to the beam. Failure can best be summarised as complete debonding of FRP strip 1 on both sides of the joint followed by joint shear failure. The test was stopped upon separation of the side cover on the beam at the beam-column interface. No clear debonding in strip 2 was observed and the final crack pattern is shown in Figure 8(a).

\section{Repaired connection RM2}

Separation of repair mortar was the primary mode of failure for repaired connection RM2, followed by FRP rupture and joint shear failure. Figure 8(b) shows the specimen post-test. No cracks were observed at the first load step; however, cracks started to appear at the beam column corner as the load was increased to $20 \mathrm{kN}$. Existing cracks re-opened as the load was increased to $40 \mathrm{kN}$ and as no new cracks were observed the connection was then loaded continuously to failure. Repair mortar separated from the compressed beam-column corner at a load of $55 \mathrm{kN}$, upon which the load dropped but then started to increase again with no noticeable debonding of the FRP. A second peak load of $63.8 \mathrm{kN}$ was reached when more of the repair mortar separated from the back side of the column. Rupture of FRP strip 1 followed shortly afterwards, owing to excessive rotation of the joint region. Further loading resulted in rupture of strip 3, after which the loadcarrying capacity of the connection was significantly lost and severe cracking in the joint region could be seen.

\section{Deformation response}

The load-deflection plots for the two repaired connections (RM1 and RM2) are shown along with the control connection (UM1) in Figure 9, and a summary of the peak loads are presented in Table 2. Inspection of the load-deflection curve for RM1 reveals the FRP repair was able to restore not only the stiffness of the connection but also the load-carrying capacity. In fact, the loadcarrying capacity was even enhanced by about $10 \%$, although the effectiveness was limited by FRP debonding. Although the connection had significant cracking, especially in the joint region, owing to shear failure in its unstrengthened state, the FRP was able to maintain the integrity of the connection. Debonding of the FRP was, however, a real problem that required rectification. Some comments regarding prevention of debonding consist of $(a)$ anchorage of the FRP (e.g. with FRP anchors; Kim and Smith, 2009, 2010; Smith et al., 2011; Zhang et al., 2011) in the joint region for two-dimensional connections, and $(b)$ debonding will not be an issue in three-dimensional connections owing to the presence of the transverse beams. Unlike the moderately damaged connection RM1, FRP strengthening was less effective in the severely damaged connection RM2 even through the FRP strengthening delayed the failure following the separation of repair mortar. About $66 \%$ of the original connection strength was achieved, primarily owing to the FRP. The primary mode of 


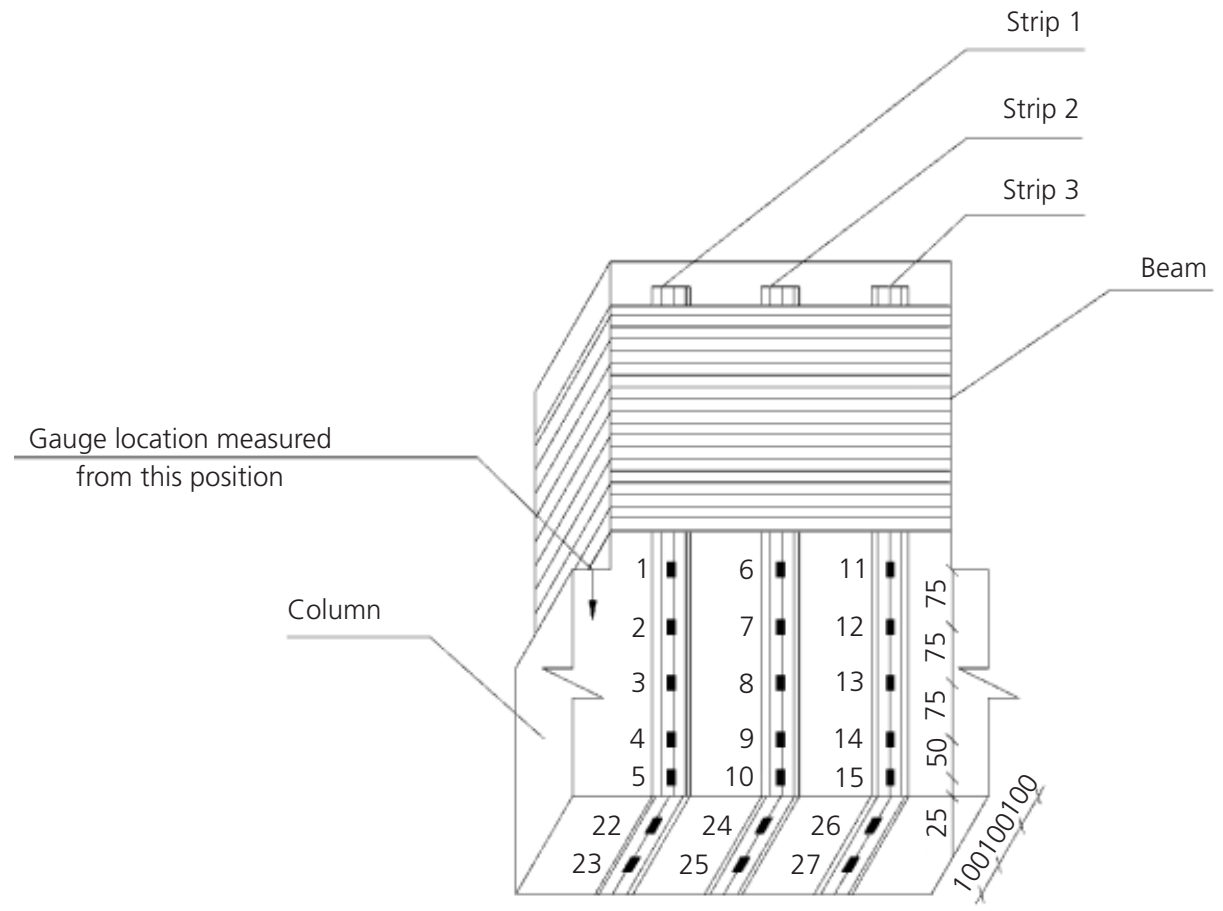

(a)

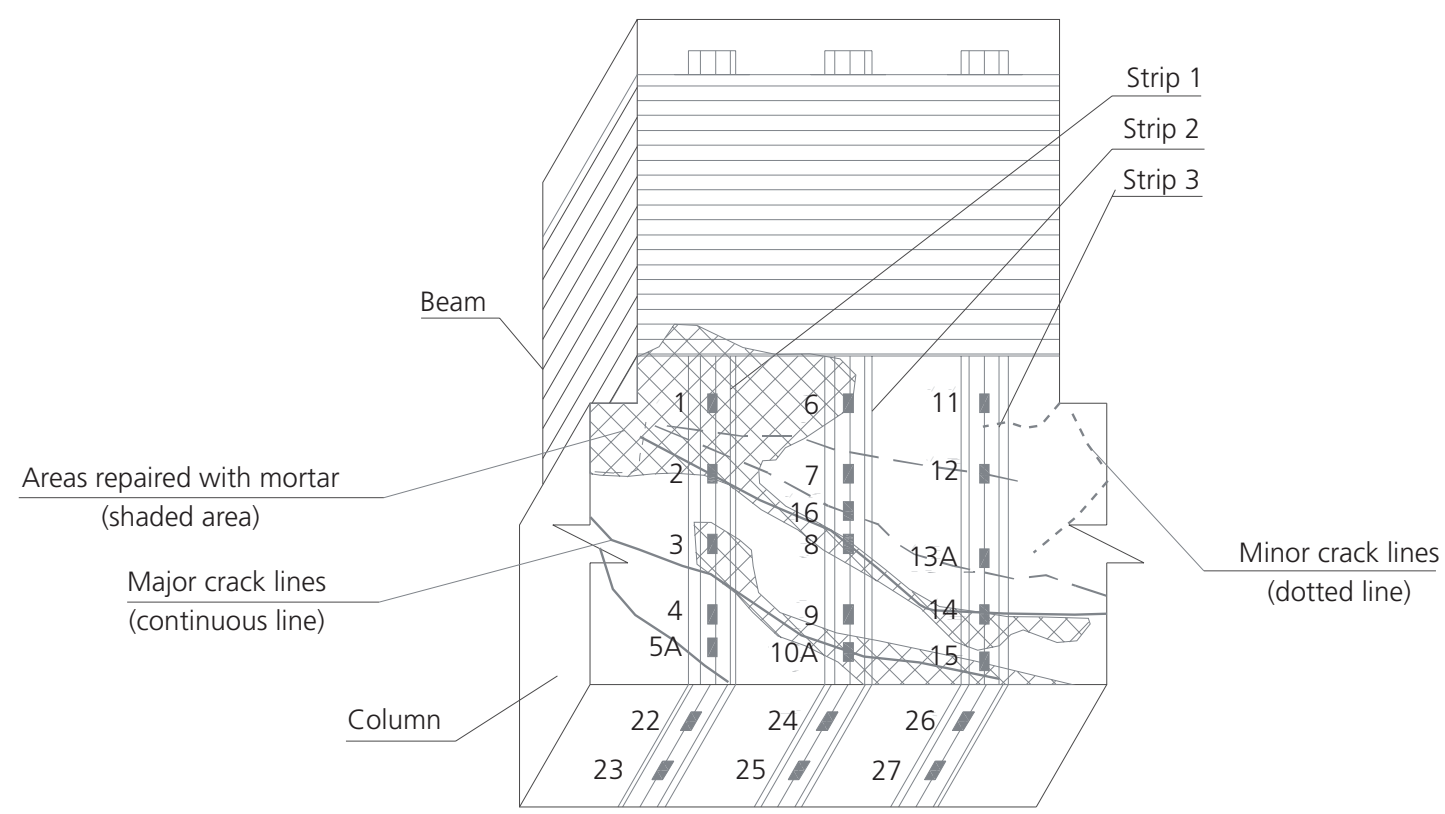

(b)

Figure 7. Beam strip repair: extent of damage (and repair) and strain gauge layout of SM2 and RM2: (a) specimen SM2; (b) specimen RM2

failure was attributable to separation of repair mortar used to fill the cracks, which was followed by FRP rupture, indicating that the concrete and mortar contributed little to load-carrying capacity and the FRP repair carried the majority of the load at an early stage. This was to be expected, considering the repair was largely cosmetic. Crack injection may enable the concrete to resist higher load and hence bring the strength of the repaired connection to at least that of the control UM1, but this can be left 
The effectiveness of FRP strips in

repairing moderately and severely

damaged RC beam-column connections

Shrestha, Smith and Samali

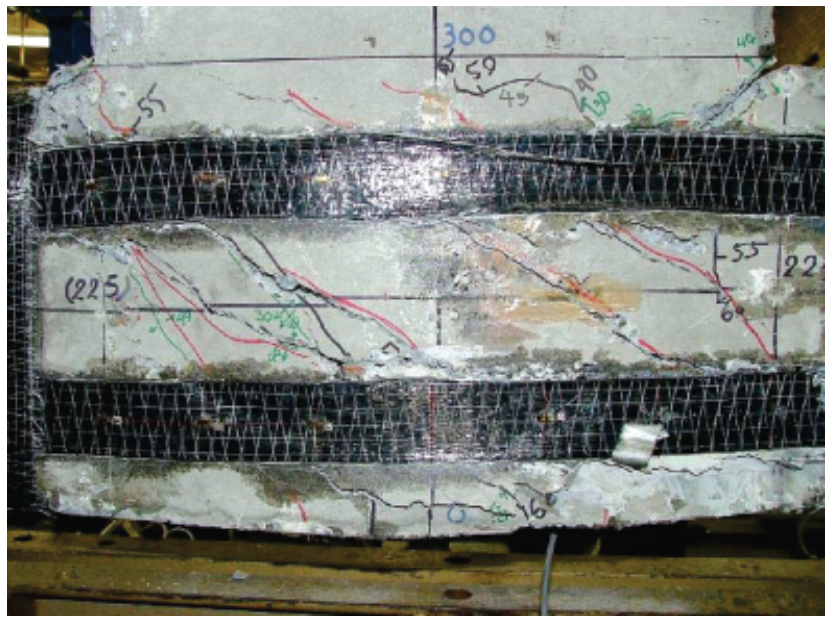

(a)

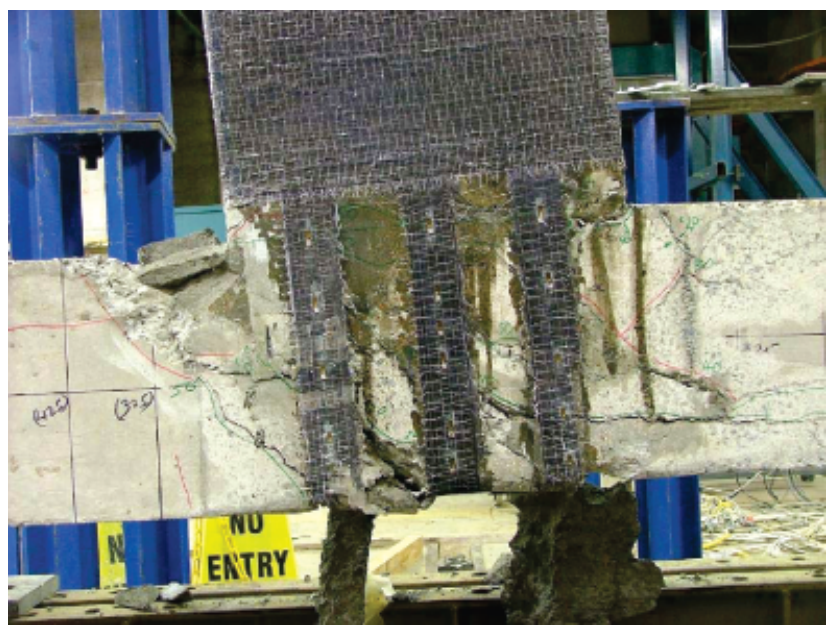

(b)

Figure 8. Photographs of failed repaired specimens: (a) RM1; (b) RM2

\section{Specimen Peak load: kN Increment: \% Deflection at} peak load: $\mathrm{mm}$

\begin{tabular}{lrrr}
\hline UM1 & $96 \cdot 4$ & - & $27 \cdot 7$ \\
SM1 & $103 \cdot 0$ & $6 \cdot 6$ & $32 \cdot 0$ \\
SM2 & $122 \cdot 0$ & $25 \cdot 6$ & $39 \cdot 1$ \\
RM1 & $106 \cdot 6$ & $10 \cdot 5$ & $29 \cdot 3$ \\
RM2 & $63 \cdot 8$ & $-33 \cdot 8$ & $79 \cdot 5$
\end{tabular}

Table 2. Summary of peak loads

for future studies. The contribution provided by the FRP (without significant contribution by the concrete), which is the issue at hand, can, however, be accurately observed from the strain gauge results, as shown in the following sub-section.

\section{Strain response}

As the contribution of the FRP for repair is being assessed in this study, selected results of FRP mounted strain gauges are presented in this section for repaired connections RM1 and RM2.

\section{Repaired connection RM1}

The distribution of strain along the length of strips 1 and 2 (refer to Figure 5 for strip and strain gauge location) on the front heavily instrumented face of the joint for the moderately damaged connection RM1 at different load levels are shown in Figures 10 and 11, respectively. Locations where the shear cracks in the joint regions intersected the FRP are also shown (shear cracks denoted by vertical dashed lines). High strains can be observed in the region adjacent to shear cracks indicating debonding of the FRP, while low FRP strain regions are those where the bond between FRP and concrete was not lost and full shear transfer between the two was maintained. Also, relatively

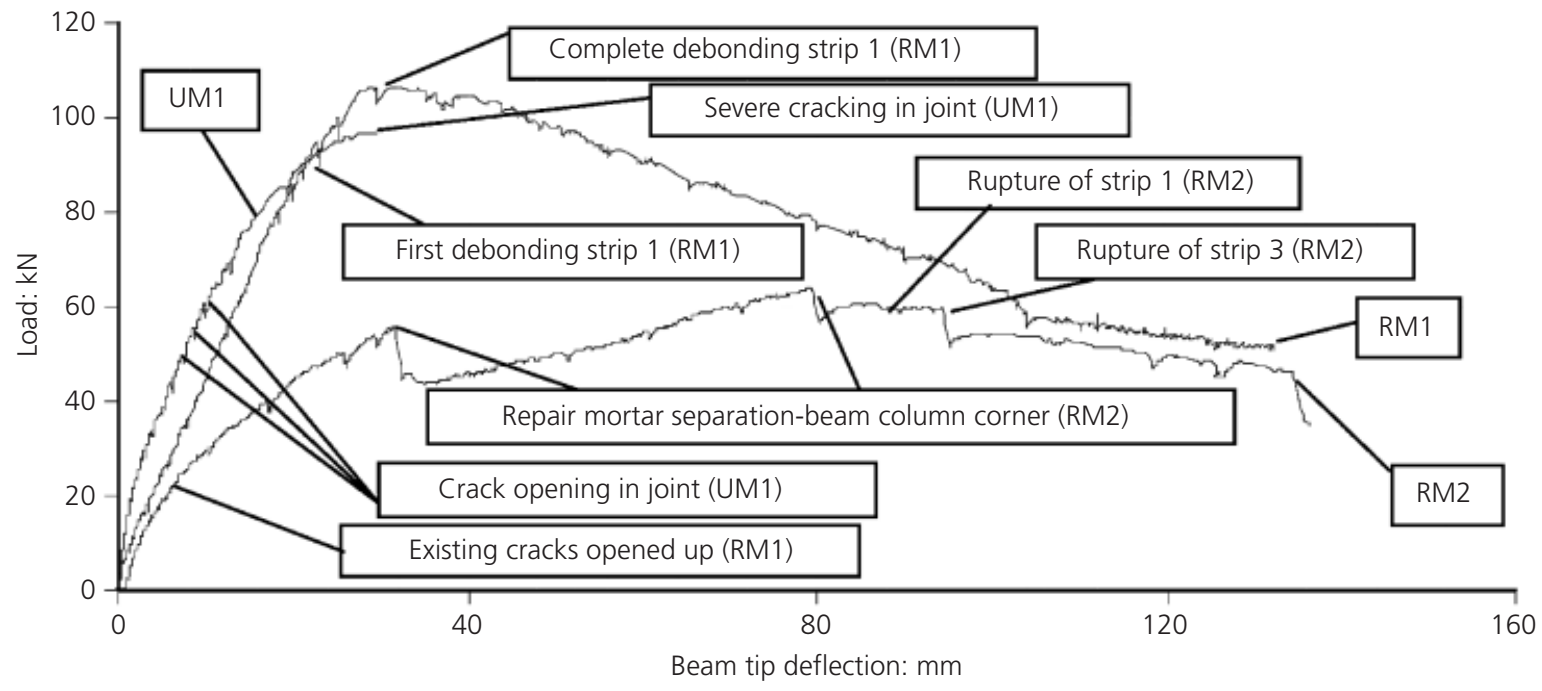

Figure 9. Load-deflection responses 


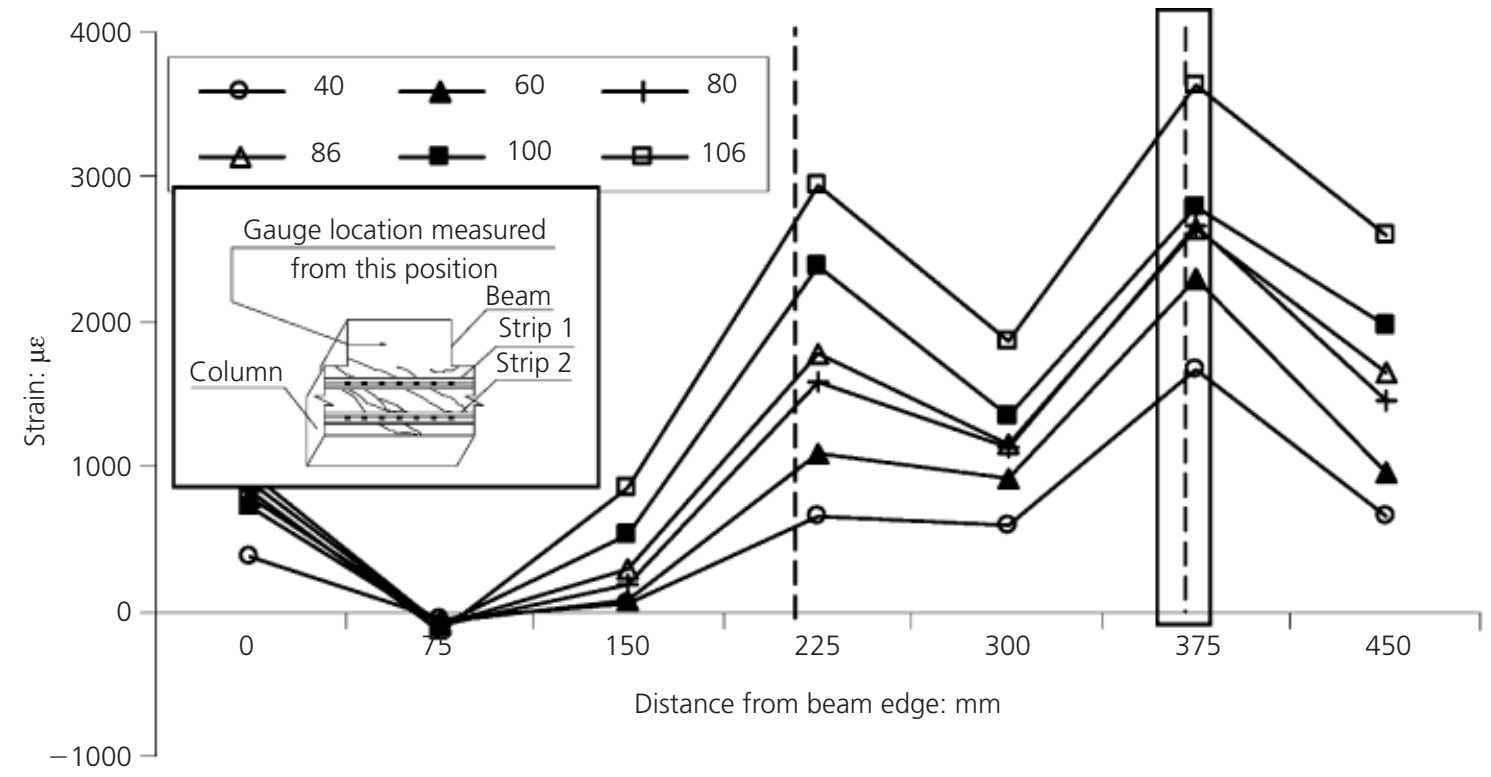

Figure 10. FRP strain distribution along strip 1: RM1

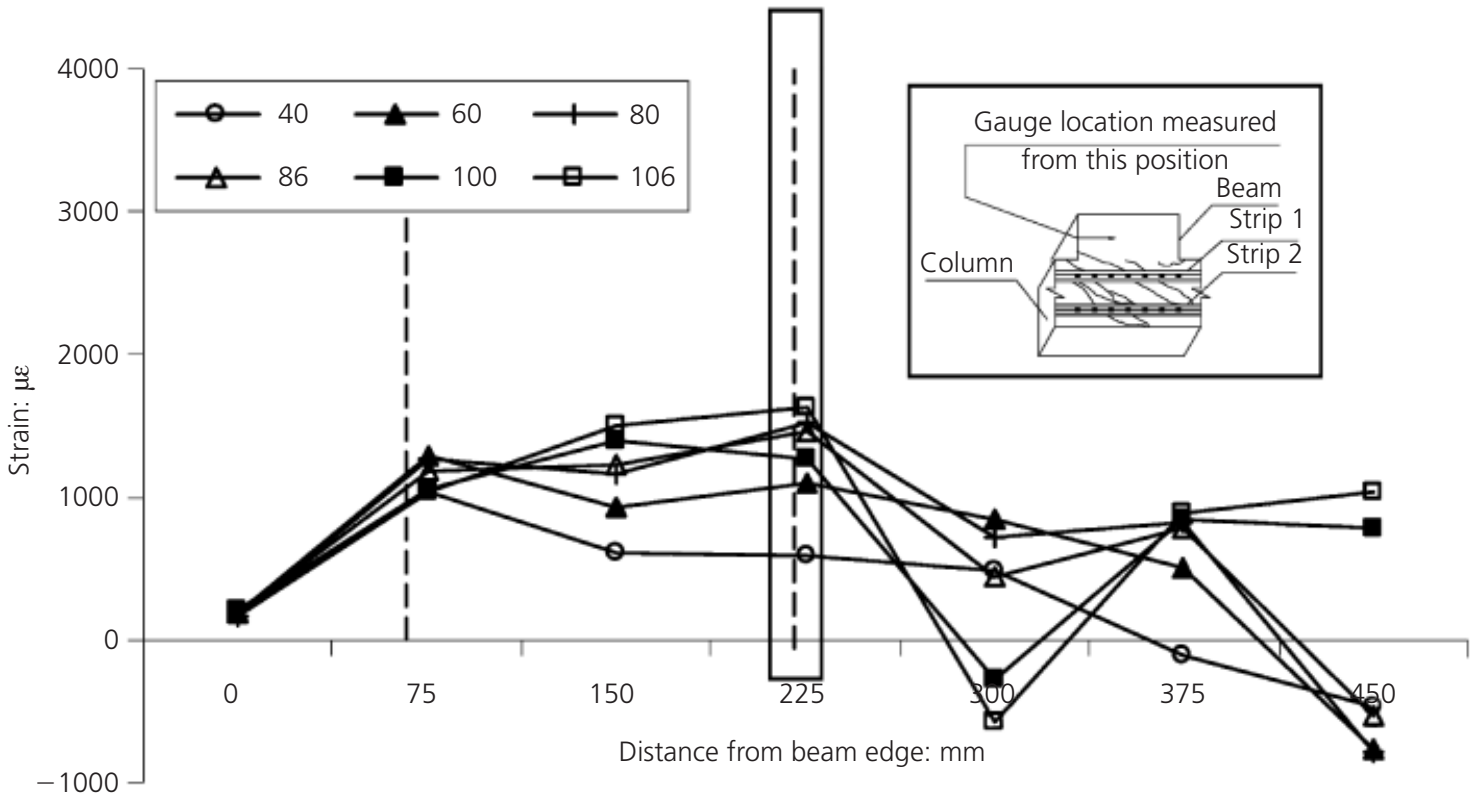

Figure 11. FRP strain distribution along strip 2: RM2

higher strain values were observed in strip 1 compared with strip 2 , indicating that strip 1 was the main shear-resisting strip. On the whole, the peak strains (as measured by the strain gauges) are well below the $1.1 \%$ rupture strain limit of the FRP. Similar behaviour of the FRP strips on the back face of the connection was observed, although only a limited number of gauges were used on these FRP strips, and the results are not shown here.

Similar strain distributions and strain levels to RM1 were ob- served in SM1, as shown in Figures 12 and 13, indicating that the behaviour of the FRP strips were similar in both repair and strengthening cases.

Finally, comparisons of the strain at identical locations for RM1 and SM1 for different levels of load are shown in Figure 14. These particular locations were chosen as they were closest to the cracks where the highest strain readings were observed (i.e. gauge 6 for strip 1 and gauge 11 for strip 2, as defined in Figure 5: 


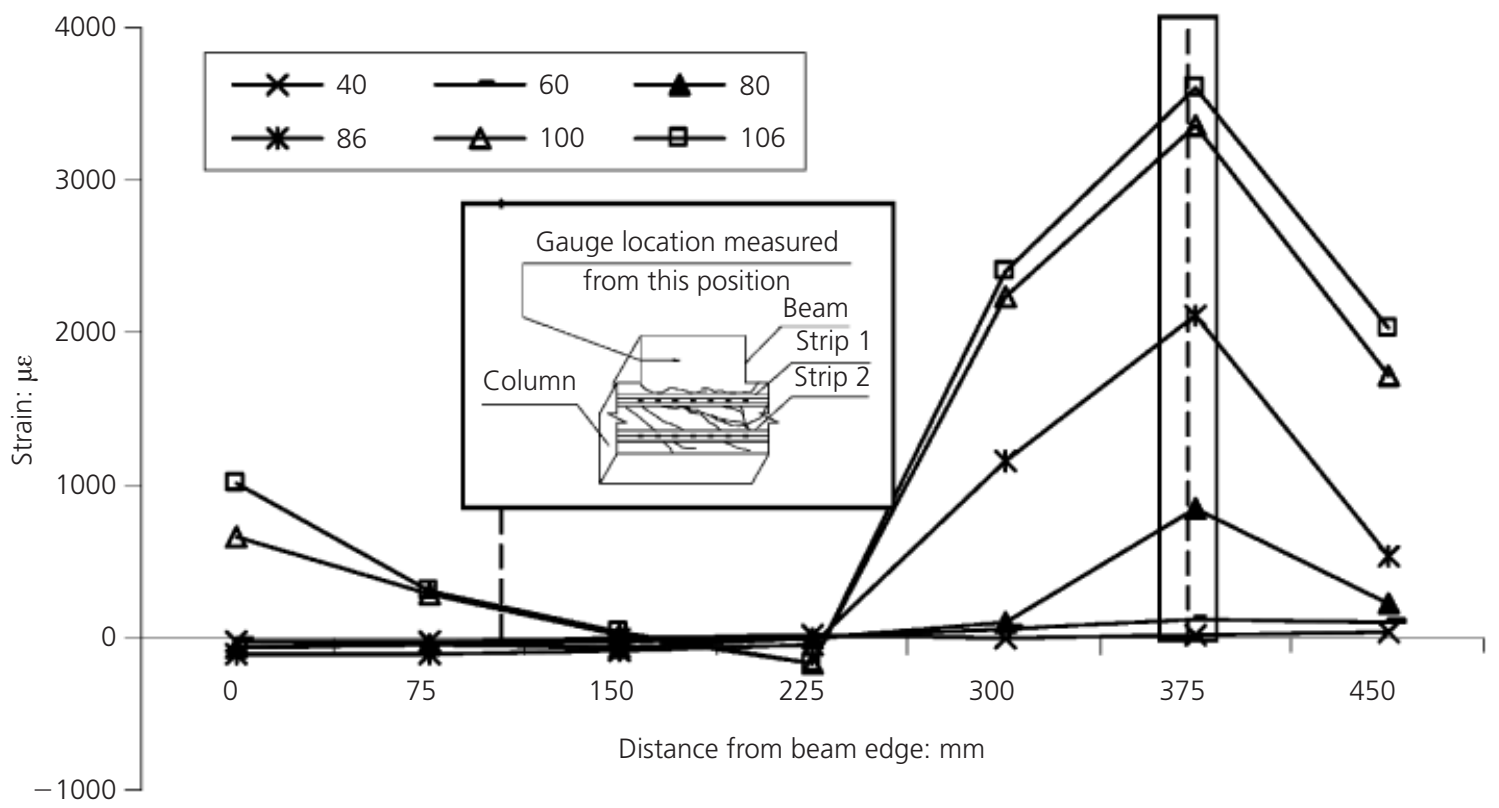

Figure 12. FRP strain distribution along strip 1: SM1

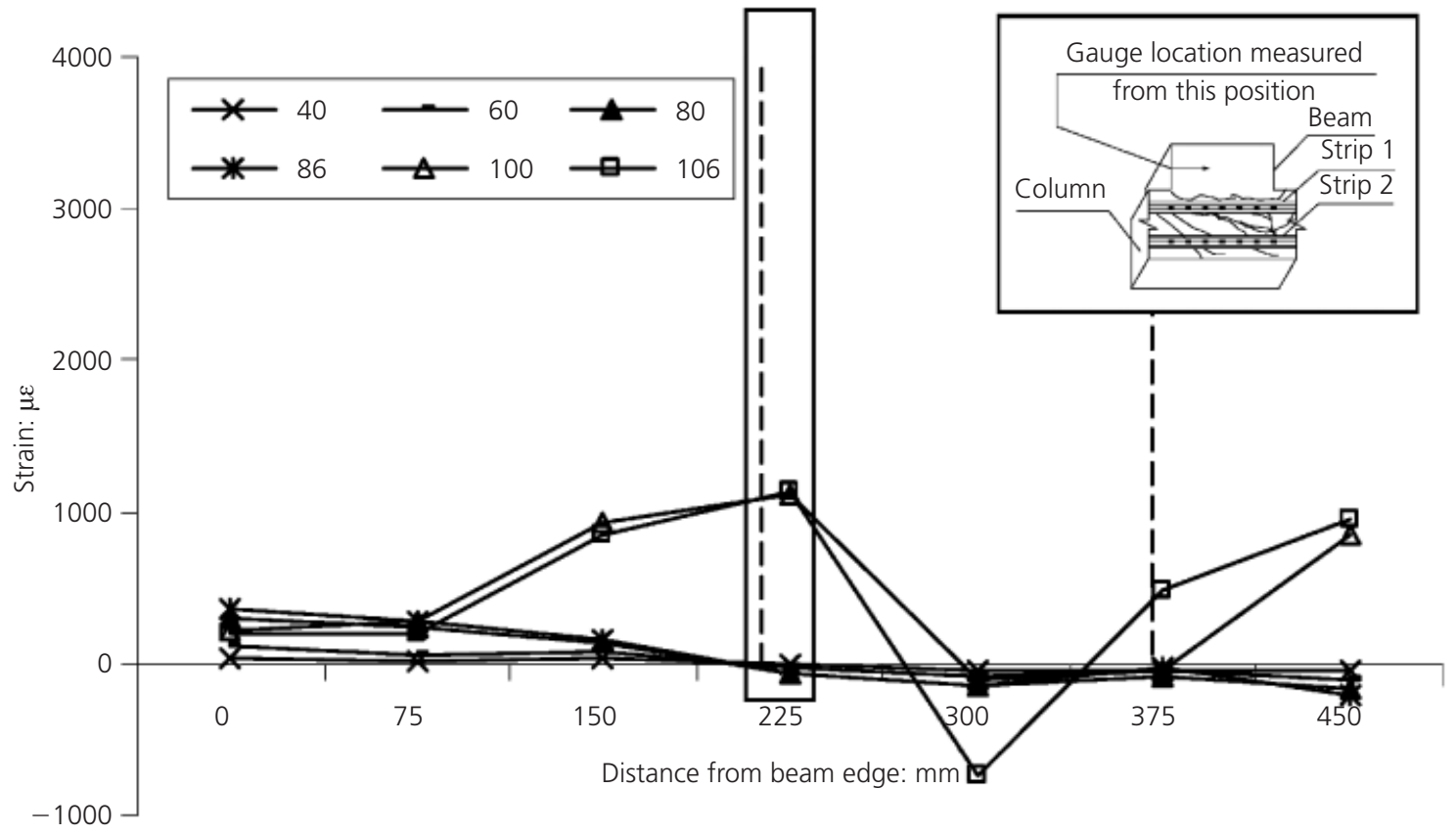

Figure 13. FRP strain distribution along strip 2: SM1

these gauges have also been defined on Figures 10 to 13 by vertically oriented rectangular boxes). Figure 14 shows that strip 1 carries significant load after about $50 \mathrm{kN}$ in connection SM1, with the same strip carrying load from the onset of loading in RM1. Similar broad conclusions can be drawn for strip 2 in SM1 and RM1, and in both cases strip 1 is the main load-carrying strip. It is hypothesised that if strip 1 is secured along it lengths, such as with FRP anchors (Smith et al., 2011), then its debonding resistance should be enhanced and the connection made to carry a higher load. 


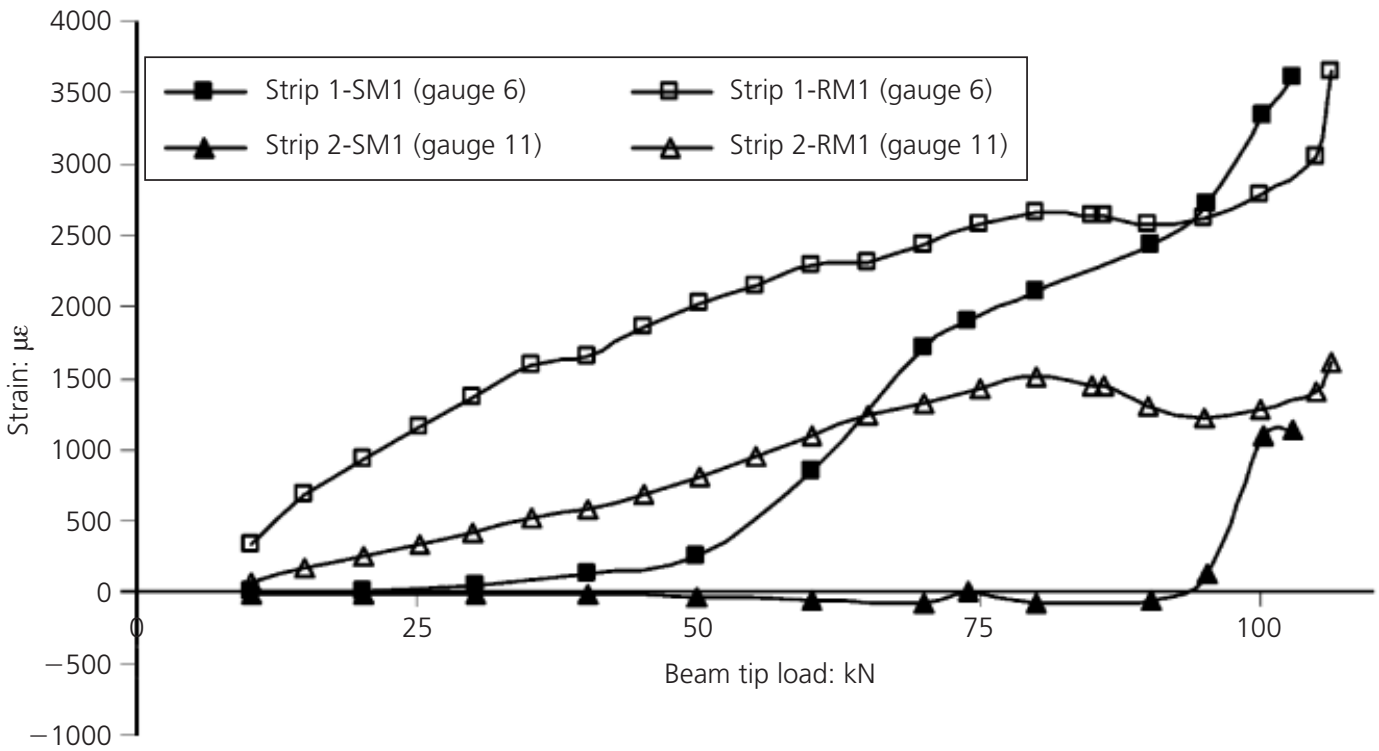

Figure 14. Comparison between RM1 and SM1 at identical

locations

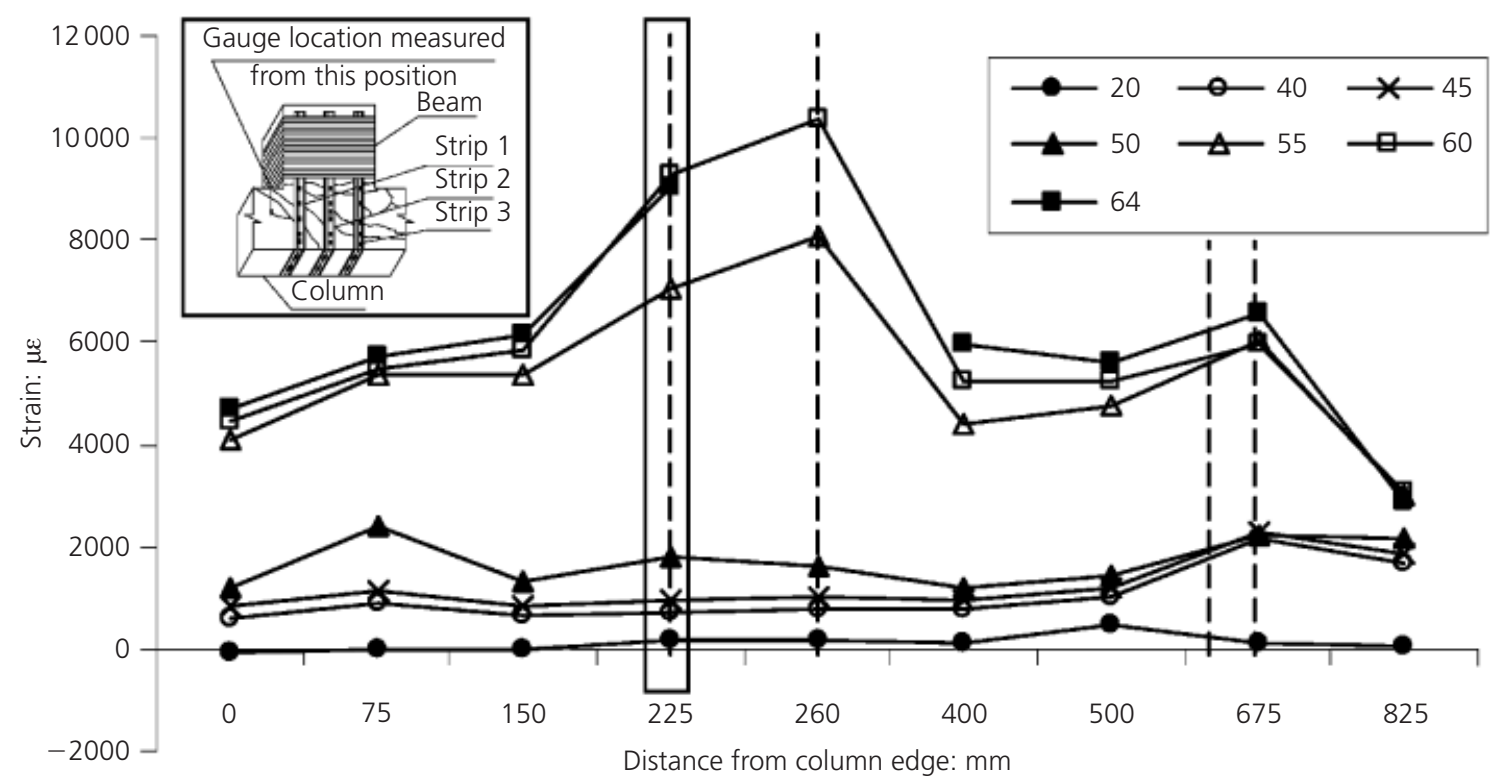

Figure 15. FRP strain distribution along strip 1: RM2

\section{Repaired connection RM2}

Distribution of strain along FRP strips 1, 2 and 3 for the severely damaged connection RM2 at different load levels are given in Figures 15, 16 and 17, respectively. Locations where the cracks intersect the FRP strips are also marked by vertical dashed lines. These plots show that there is an increase in the FRP strain, especially for strips 1 and 3, corresponding to the separation of repair mortar at $55 \mathrm{kN}$ load, which indicates that the majority of the load was carried by FRP strips then onwards.
The high strain values for strip 1 are approaching the $1 \cdot 1 \%$ rupture strain limit of the FRP. In addition, the lower levels of strain for strip 2 suggest the strip is less effective than the other two strips.

Figures 18, 19 and 20 show the distribution of strain for strips 1 , 2 and 3 for connection SM2. The difference in behaviour of the FRP strips between specimens RM2 and SM2 is obvious. In the latter case the shear strength of the concrete is more pronounced 


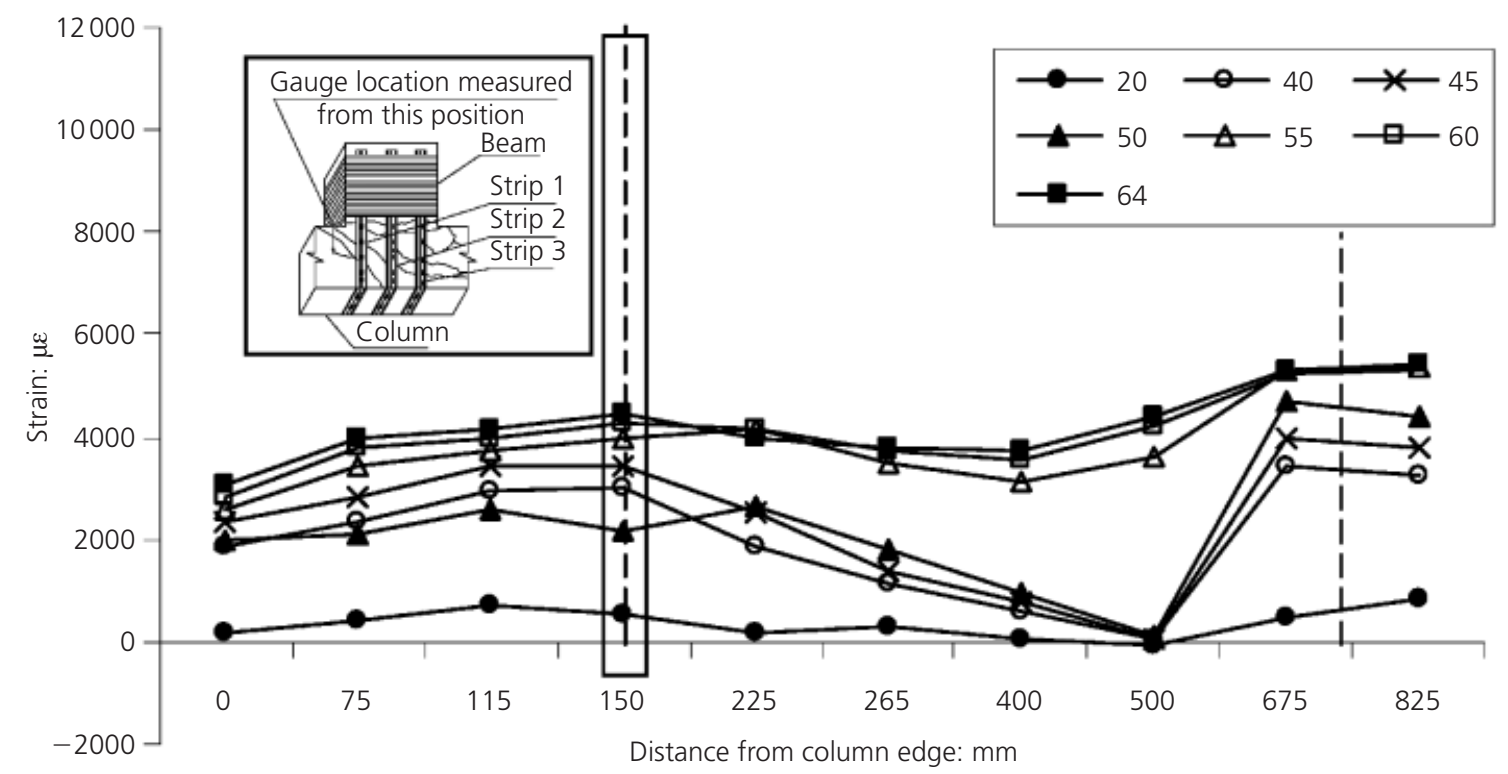

Figure 16. FRP strain distribution along strip 2: RM2

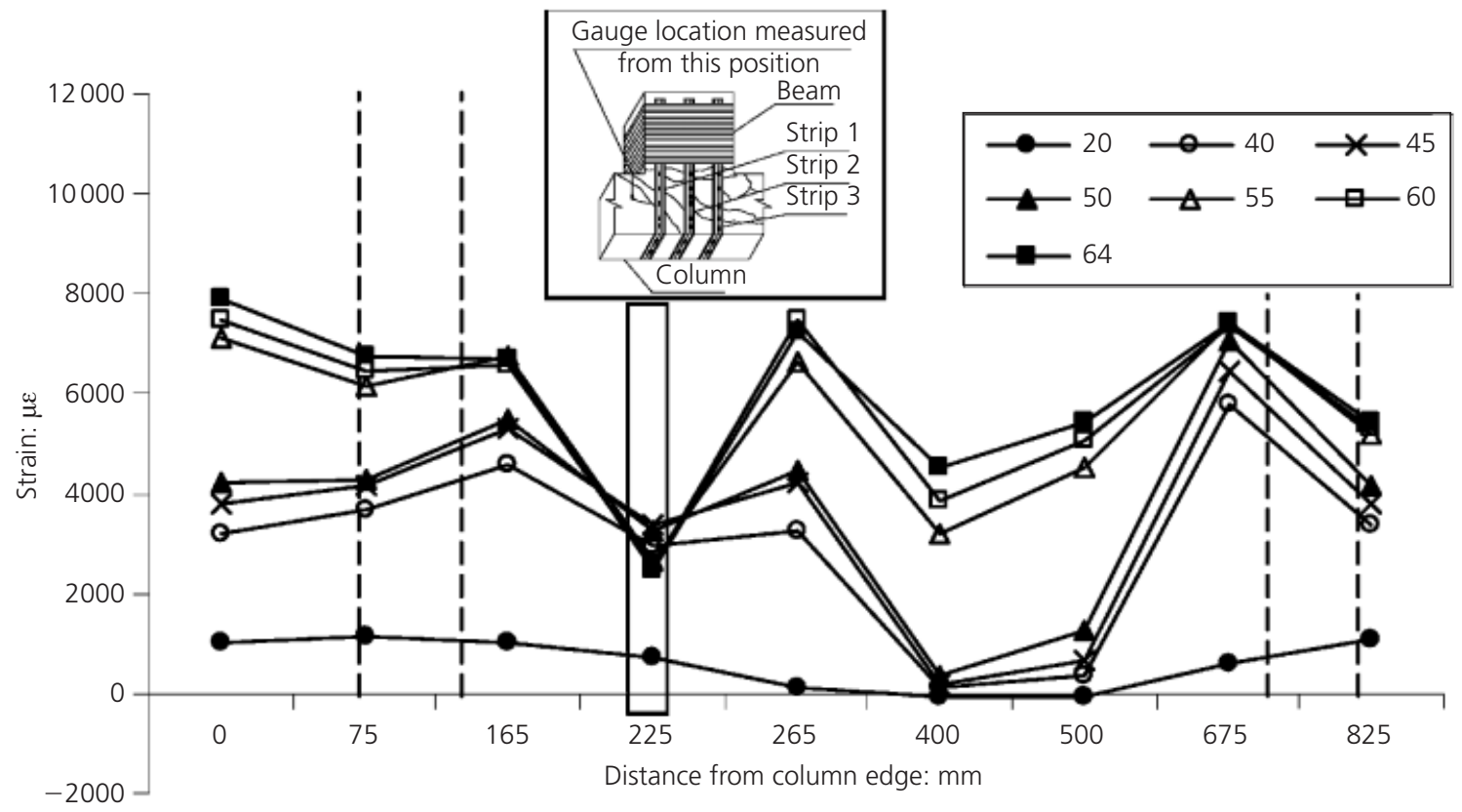

Figure 17. FRP strain distribution along strip 3: RM2

and ensures the level of strain in the FRP does not reach the rupture strain level, unlike the former case.

In the case of connection SM2, the shear strength of the concrete limits the level of strain in the FRP until the joint is severely cracked after reaching the peak load value. For connection RM2, because of the original cracks in the joint region, FRP strips were subjected to high levels of strain from the beginning of the test resulting in rupture of the FRP strips at much lower load. Comparison of strain at the same locations close to the cracks where highest strains were recorded (i.e. gauges 4 for strip 1, gauge 8 for strip 2, and gauge 14 for strip 3 as defined in Figures 7(a) and 7(b)) for connections RM2 and SM2 for all three strips are given in Figure 21. In 


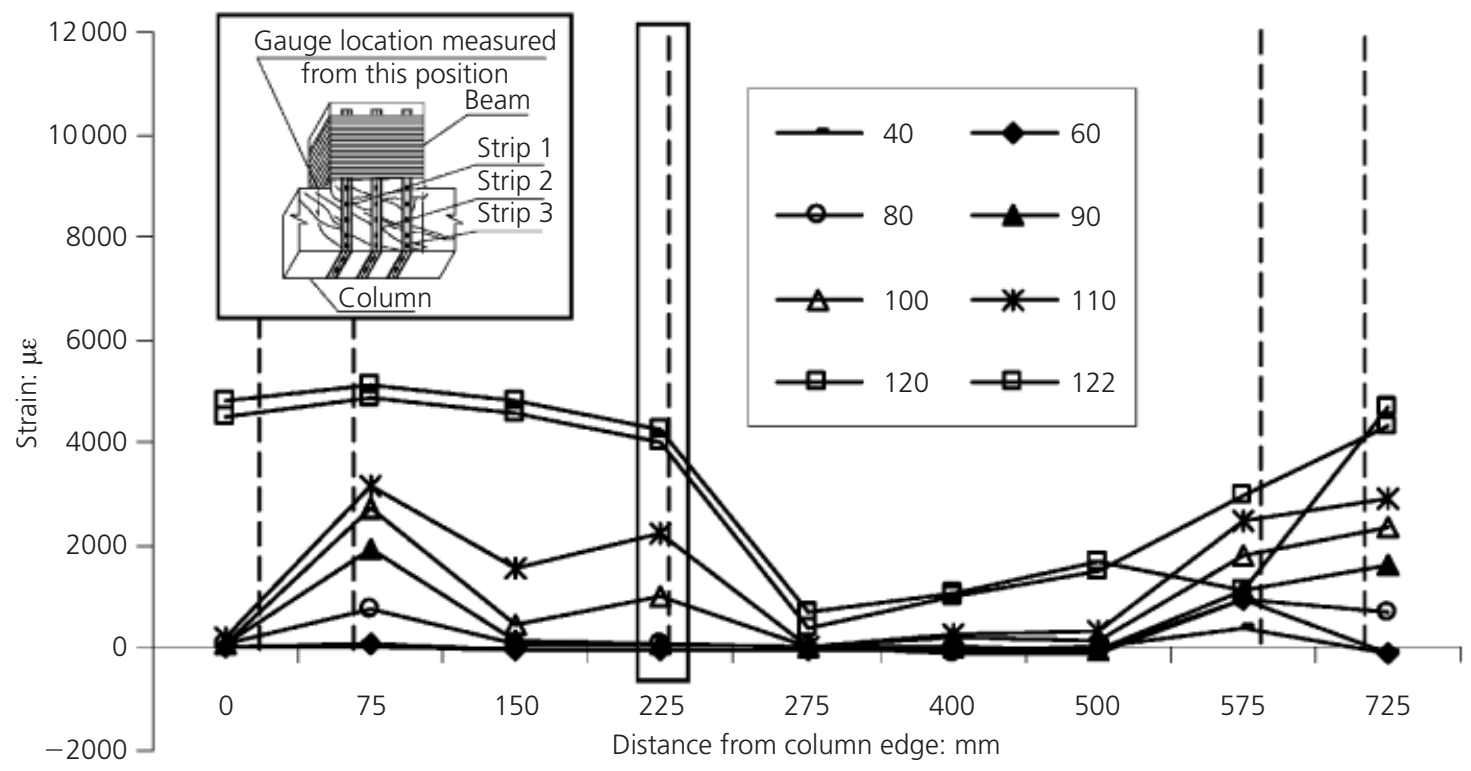

Figure 18. FRP strain distribution along strip 2: SM2

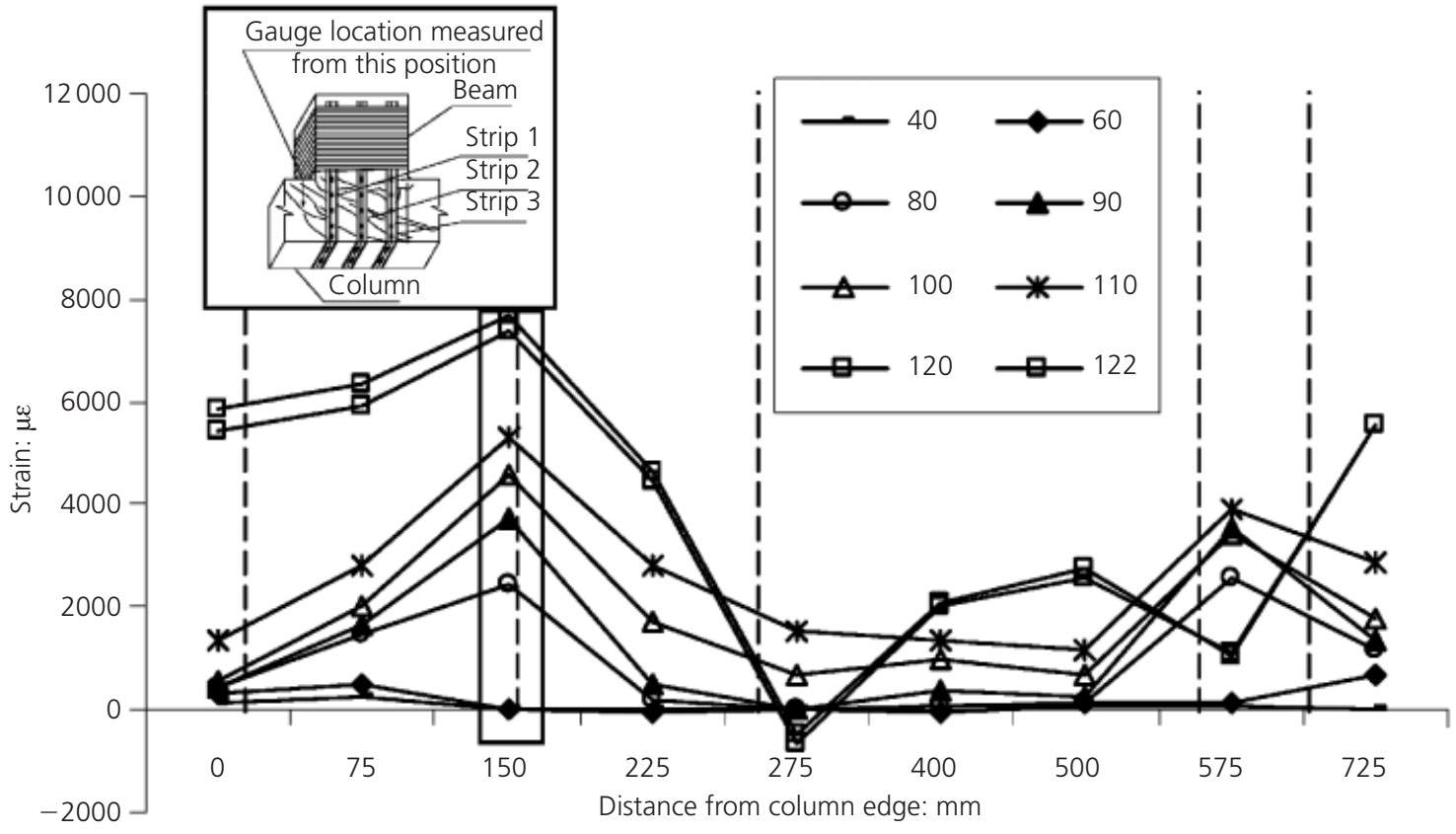

Figure 19. FRP strain distribution along strip 2: SM2

all cases the FRP resists load much earlier in RM2 than SM2. On the whole, beam oriented strips are much more effective than column oriented strips as the level of strain developed is much higher, thus leading to a better use of the FRP. Despite the FRP strips debonding, before rupture, they are still able to achieve rupture strains and are able to resist joint shear distortion better than column oriented strips.

\section{Conclusions}

The following comments can be made and conclusions drawn from this study.

(a) The effectiveness of FRP strips for repairing moderately damaged exterior connections was demonstrated in this study. The FRP repair, however, was not fully able to restore the 


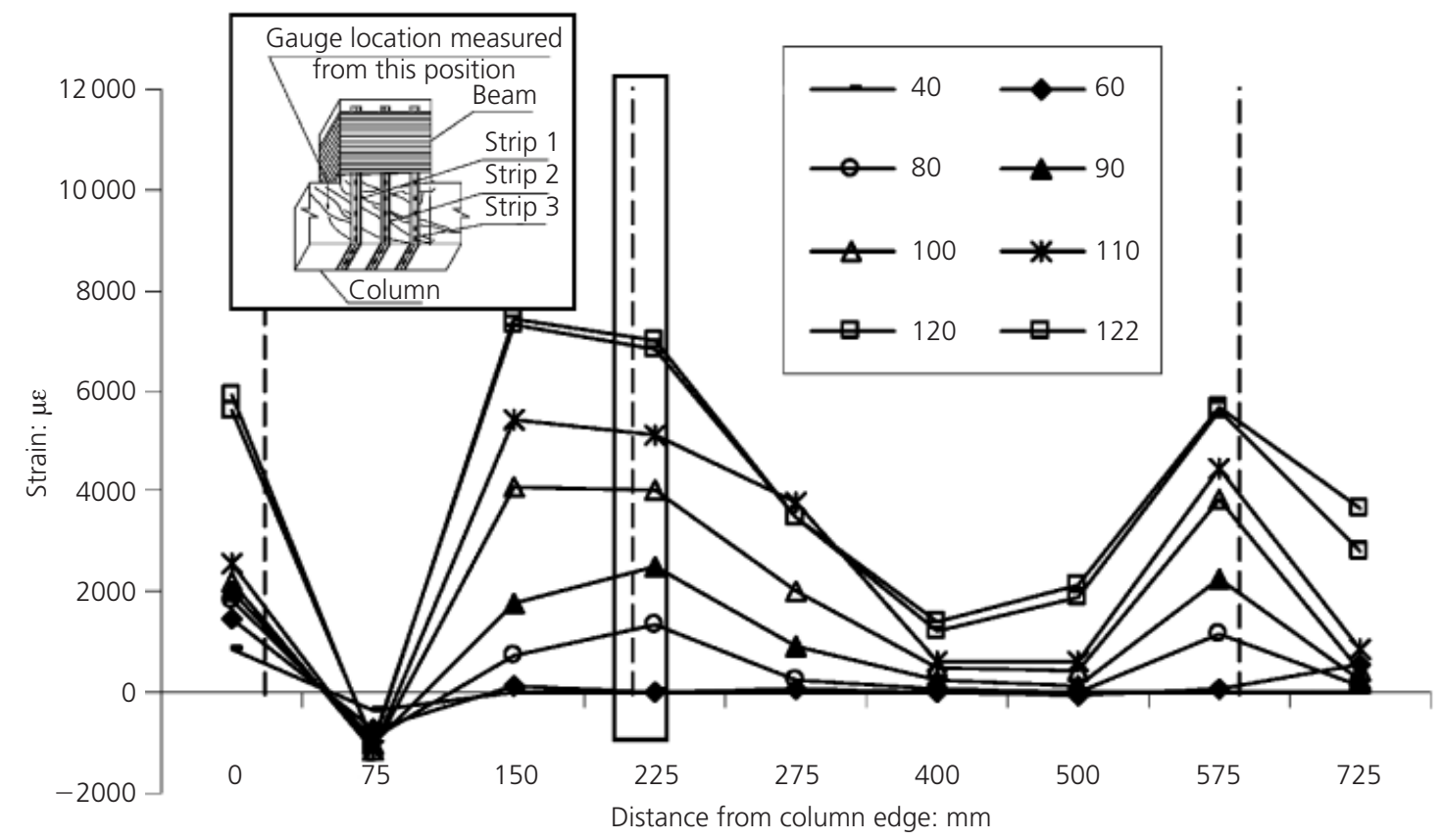

Figure 20. FRP strain distribution along strip 3: SM2

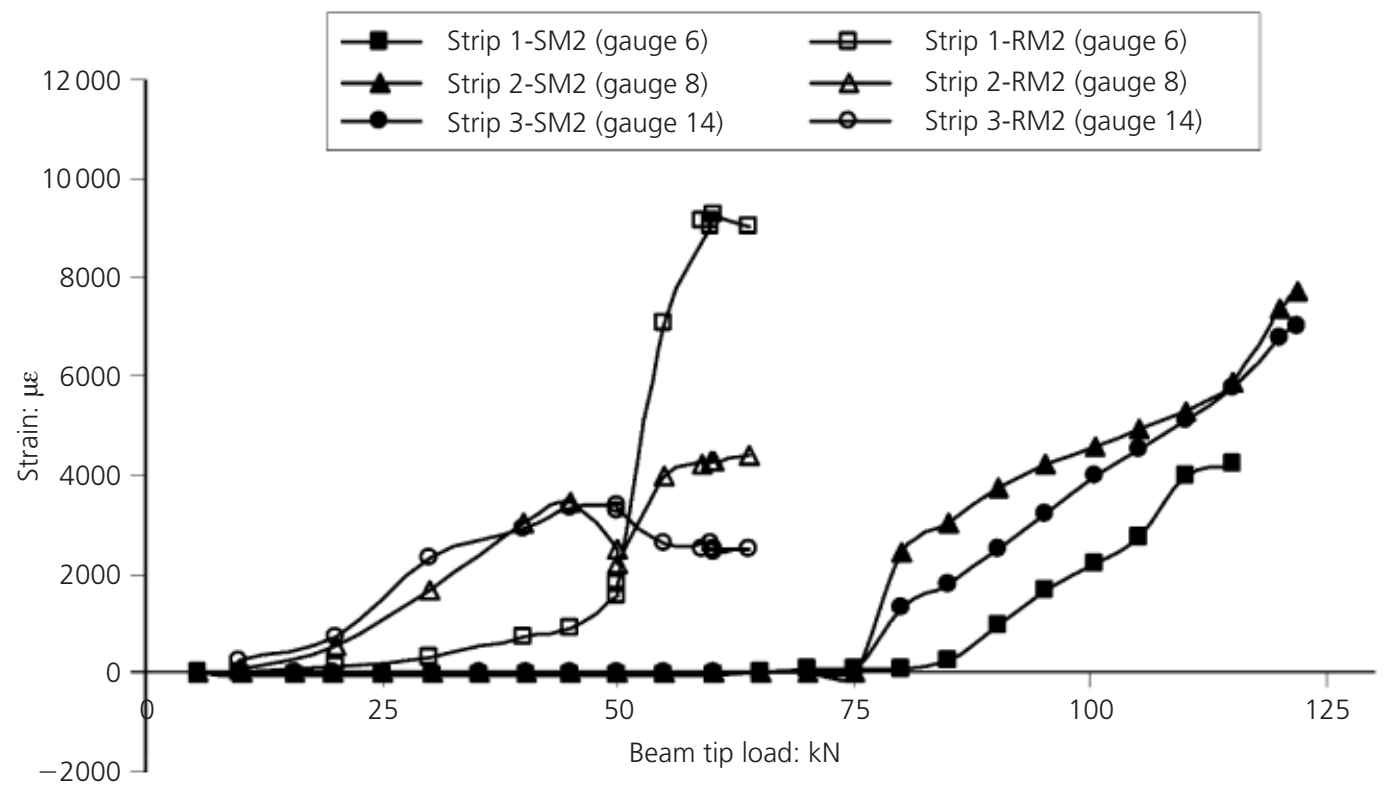

Figure 21. Strain comparison between RM2 and SM2 at identical locations

capacity of the severely damaged connection, although this was not the intention of the study.

(b) For the moderately damaged connection, extensive debonding of the FRP limited the effectiveness of the FRP, despite end anchorage preventing the strips from completely debonding. Preventing or delaying such debonding (e.g. by way of addition of FRP anchors) would enhance the effectiveness of the FRP. Debonding would be eliminated if FRP strips were used to repair three-dimensional connections owing to the confinement provided by the transverse beams.

(c) Comparison of the strain distributions in column-oriented FRP strips for repair of the moderately damaged connection 
to the accompanying strengthened connection showed similar behaviour.

(d) For the severely damaged connection, the primary mode of failure was attributable to separation of repair mortar then FRP rupture.

(e) Comparison of stress distribution in the FRP between beamoriented strips for repair of the severely damaged connection to the accompanying strengthened connection showed the FRP to carry the majority of the load for the former, which is why rupture occurred. As such, a comprehensive repair method to close the cracks effectively, such as crack injection, should enhance the effectiveness of the entire repair by allowing both FRP and concrete to contribute to the shear strength of the connection.

$(f)$ Selected experimental results have been presented in detail in order to assist researchers in the calibration of future analytical models and also to assist in the numerical simulation of damaged RC connections which have been repaired with FRP composites.

\section{Acknowledgement}

This project was funded by Australian Research Council (ARC) Discovery Grant DP0559567. The financial assistance of the ARC is gratefully acknowledged.

\section{REFERENCES}

Al-Salloum YA and Almusallam TH (2007) Seismic response of interior RC beam-column joints upgraded with FRP sheets. I: experimental study. Journal of Composites for Construction ASCE 11(6): 575-589.

Antonopoulos CP and Triantafillou TC (2003) Experimental investigation of FRP-strengthened RC beam-column joints. Journal of Composites for Construction, ASCE 7(1): 39-49.

ASTM (American Society for Testing and Materials) (2004) ASTM ES-04: Standard test methods for tension testing of metallic materials. ASTM, Pennsylvania, USA.

ASTM (American Society for Testing and Materials) (2000) ASTM 3039/D3039M: Standard test method for tensile properties of polymer matrix composites materials. ASTM, Pennsylvania, USA.

Engindeniz M, Kahn LF and Zureick AH (2005) Repair and strengthening of reinforced concrete beam-column joints: state of the art. ACI Structural Journal 102(2): 1-14.

French CW, Thorp GA and Tsai WJ (1990) Epoxy repair techniques for moderate earthquake damage. ACI Structural Journal 87(4): 416-424.

Ghobarah A and El-Amoury T (2005) Seismic rehabilitation of deficient exterior concrete frame joints. Journal of Composites for Construction, ASCE 9(5): 408-416.

Granata PJ and Parvin A (2001) An experimental study on Kevlar strengthening of beam-column connections. Composite Structures 53(5): 163-171.

Kim SJ and Smith ST (2009) Behaviour of handmade FRP anchors under tensile load in uncracked concrete. Advances in Structural Engineering, APFIS-09 Special Issue 12(6): 845865.

Kim SJ and Smith ST (2010) Pullout strength models for FRP anchors in uncracked concrete. Journal of Composites for Construction, ASCE 14(4): 406-414.

Paulay T and Priestley MJN (1992) Seismic Design of Reinforced Concrete and Masonry Buildings. Wiley, New York.

Shrestha R (2009) Behaviour of RC Beam-column Connections Retrofitted with FRP Strips. Doctor of Philosophy Dissertation, Department of Civil and Environmental Engineering, University of Technology Sydney, Australia.

Shrestha R, Smith ST and Samali B (2009) Strengthening of RC beam-column connections with FRP strips. Proceedings of the Institution of Civil Engineers, Structures and Buildings 162(SB5): 323-334.

Smith ST and Shrestha R (2006) Review of FRP-strengthened RC beam-column connections. Proceedings of the $3 \mathrm{rd}$ International Conference on FRP Composites in Civil Engineering, CICE 2006, Miami, USA, 13-15 December 2006, 661-664.

Smith ST, Hu S, Kim SJ and Sevacino R (2011) FRP-strengthened RC slabs anchored with FRP anchors. Engineering Structures 33(4): $1075-1087$.

Tsonos AG and Styliandis K (2002) Seismic retrofit of beam-tocolumn joints with high strength fibre jackets. European Earthquake Engineering 16(2): 56-72.

Zhang HW, Smith ST and Kim SJ (2011) Optimisation of carbon and glass FRP anchor design. Construction and Building Materials, FRPRCS9 Special Edition, doi: 10.1016/ j.conbuildmat.2010.11.100.

\footnotetext{
WHAT DO YOU THINK?

To discuss this paper, please submit up to 500 words to the editor at www.editorialmanager.com/macr by 1 March 2012. Your contribution will be forwarded to the author(s) for a reply and, if considered appropriate by the editorial panel, will be published as a discussion in a future issue of the journal.
} 